\title{
Trends in particle-phase liquid water during the Southern Oxidant and Aerosol Study
}

\author{
T. K. V. Nguyen ${ }^{1}$, M. D. Petters ${ }^{2}$, S. R. Suda ${ }^{2}$, H. Guo ${ }^{3}$, R. J. Weber ${ }^{3}$, and A. G. Carlton ${ }^{1}$ \\ ${ }^{1}$ Department of Environmental Sciences, Rutgers University, New Brunswick, NJ 08901, USA \\ ${ }^{2}$ Department of Marine Earth and Atmospheric Sciences, North Carolina State University, Raleigh, NC 27695, USA \\ ${ }^{3}$ School of Earth and Atmospheric Sciences, Georgia Institute of Technology, Atlanta, GA 30332, USA \\ Correspondence to: M. D. Petters (markus_petters@ncsu.edu)
}

Received: 30 January 2014 - Published in Atmos. Chem. Phys. Discuss.: 18 March 2014

Revised: 4 September 2014 - Accepted: 8 September 2014 - Published: 16 October 2014

\begin{abstract}
We present in situ measurements of particle-phase liquid water. Measurements were conducted from 3 June to 15 July 2013 during the Southern Oxidant and Aerosol Study (SOAS) in the southeastern US. The region is photochemically active, humid, dominated by biogenic emissions, impacted by anthropogenic pollution, and known to contain high concentrations of organic aerosol mass. Measurements characterized mobility number size distributions of ambient atmospheric aerosols in three states: unperturbed, dry, and dry-humidified. Unperturbed measurements describe the aerosol distribution at ambient temperature and relative humidity. For the dry state, the sample was routed through a cold trap upstream of the inlet then reheated, while for the dry-humidified state the sample was rehumidified after drying. The total volume of water and semi-volatile compounds lost during drying was quantified by differencing dry and unperturbed volumes from the integrated size spectra, while semi-volatile volumes lost during drying were quantified differencing unperturbed and dry-humidified volumes. Results indicate that particle-phase liquid water was always present. Throughout the SOAS campaign, median water mass concentrations at the relative humidity $(\mathrm{RH})$ encountered in the instrument typically ranged from 1 to $5 \mu \mathrm{g} \mathrm{m} \mathrm{m}^{-3}$ but were as high as $73 \mu \mathrm{g} \mathrm{m}^{-3}$. On non-raining days, morning time (06:00-09:00) median mass concentrations exceeded $15 \mu \mathrm{g} \mathrm{m}^{-3}$. Hygroscopic growth factors followed a diel cycle and exceed 2 from 07:00 to 09:00 local time. The hygroscopicity parameter kappa ranged from 0.14 to 0.46 and hygroscopicity increased with increasing particle size. An observed diel cycle in kappa is consistent with changes in aerosol inorganic content and a dependency of the hygro-
\end{abstract}

scopicity parameter on water content. Unperturbed and dryhumidified aerosol volumes did not result in statistically discernible differences, demonstrating that drying did not lead to large losses in dry particle volume. We anticipate that our results will help improve the representation of aerosol water content and aqueous-phase-mediated partitioning of atmospheric water-soluble gases in photochemical models.

\section{Introduction}

Atmospheric aerosols affect human health and welfare, global climate, visibility, and ecosystems. Aerosols are either directly emitted or form in the atmosphere through a myriad of chemical reactions involving a variety of anthropogenic and biogenic precursors (Kanakidou et al., 2005; Hallquist et al., 2009). As a consequence, atmospheric aerosols consist of a mix of chemically diverse lower and higher volatility compounds. While low-volatility species remain predominantly in the particle phase, semi-volatile compounds, including water, undergo equilibrium partitioning between the condensed and gaseous phases (Murphy et al., 1998; Pöschl, 2005; Robinson et al., 2007). Particle-phase liquid water and its interactions with aerosol chemical composition is associated with many aerosol health and welfare effects: acid deposition (Calvert et al., 1985), impaired visibility through light scattering (e.g., Malm et al., 1994; Park et al., 2004; Pitchford et al., 2007), climate through effects on aerosol optical depth (Pilinis et al., 1995, Leibensperger et al., 2012), and climate through effects on cloud condensation and ice nuclei (e.g., Cruz and Pandis, 1997; Pöschl, 2005). Quantitative 
characterization of ambient aerosol size, mass, and chemical composition, including water content, is essential to adequately understand the fate and transport of chemicals in the Earth's atmosphere, and to develop effective strategies that mitigate aerosol-related problems.

Water is an abundant atmospheric constituent that is present in the condensed phase as a function of relative humidity (RH), temperature, aerosol concentration, and chemical composition (Zhou et al., 2011). Liquid water is estimated to represent a substantial fraction of total tropospheric aerosol volume at RH > 85\% (Kreidenweis et al., 2008) and is predicted to exceed total aerosol dry mass by 2 to 3 times globally (Liao and Seinfeld, 2005). The aqueous phase also provides a medium for the partitioning of polar, watersoluble gas-phase species (Asa-Awuku et al., 2010; Prisle et al., 2010), thus potentially facilitating secondary organic aerosol (SOA) formation (Carlton et al., 2009; Ervens et al., 2011; Carlton and Turpin, 2013). Despite the abundance and importance of aerosol water, it is not routinely measured, actual mass concentrations are not well known, and model predictions are poorly constrained.

The role of water in SOA formation in a particular environment is complex. In addition to the availability and relative abundance of particle-phase liquid water, SOA enhancement depends on the amount of semi-volatile and water-soluble gas-phase material (Carlton and Turpin, 2013). For absorptive partitioning, SOA formation is dependent of the activity coefficient of the organic in the solution (Pankow et al., 2001; Barley et al., 2009). The presence of inorganic material mixed with hydrophobic organic compounds may lead to liquid-liquid phase separation (Bertram et al., 2011) and the presence of liquid-liquid equilibria may influence partitioning (Prisle et al., 2010). Partitioning of water-soluble material is also influenced by the presence of inorganic material through salting effects (Lim et al., 2010; Knote et al., 2014). Semi-volatiles and dissolved gases that are associated with the aqueous phase may be lost by particle drying, which could hamper measurement and predictions of cloud condensation nuclei from dried aerosol streams (Topping and McFiggans, 2012).

Several techniques exist to measure aerosol hygroscopic properties. In general, hygroscopicity measurements characterize the change in aerosol properties in response to perturbations in RH. Sorooshian et al. (2008) provide a detailed overview of the different available techniques. Broadly, the approaches can be classified into methods that probe single sizes and methods that probe the entire aerosol. Popular single-size methods include the hygroscopicity tandem differential mobility analyzer (HTDMA) technique (Liu et al., 1978; Rader and McMurry, 1986; Suda and Petters, 2013), the laminar flow tube approach (Stratmann et al., 2004; Wex et al., 2005), and the single-particle levitation approaches (Tang, 1996; Mitchem and Reid, 2008). The HTDMA technique has been routinely deployed in field experiments, providing rich data sets for particle hygroscopic growth factors in a wide range of environments (e.g., McMurry and Stolzenburg, 1989; Berg et al., 1998; Dick et al., 2000; Swietlicki et al., 2008, and references therein). Popular methods that characterize the change in the entire aerosol with humidity include humidified nephelometry (Rood et al., 1985), aerosol hydration spectrometry (Stanier et al., 2004; Hegg et al., 2008; Snider and Petters, 2008; Engelhart et al., 2011), and gravimetric methods (Mikhailov et al., 2013). Single-size methods are generally more precise and less ambiguous to interpret relative to bulk techniques. Bulk techniques, however, are useful because they characterize the entire aerosol rather than a subset and thus are needed to directly measure total water volume.

Here we report measurements obtained with an aerosol preconditioning system coupled with a scanning mobility particle sizer (SMPS) to explicitly measure total aerosol liquid water and to estimate the loss of semi-volatile compound volume during particle drying. Our study is motivated by the need to explore the hypothesis that particle water enhances biogenic SOA volume through aqueous-mediated partitioning of biogenically derived organic species as the result of anthropogenic perturbations (Carlton and Turpin, 2013). The humid, photochemically active summer of the southeastern US is ideal for conducting this study. Biogenic SOA mass concentrations are typically large (Lewis et al., 2004; Kleindienst et al., 2007; Ding et al., 2008), demonstrate positive relationships to RH (Hatch et al., 2011), and have been shown to be enhanced by the presence of sulfates and nitrates that affect particle water uptake (Chan et al., 2010). Further, model predictions suggest liquid water mass concentrations are high (Carlton and Turpin, 2013), and that aqueous-phase water attributed to anthropogenic sulfate may influence biogenic SOA mass (Carlton et al., 2010; Hoyle et al., 2011) in the area.

The instrument was deployed as a part of the Southern Oxidant and Aerosol Study (SOAS), a collaborative field campaign during the summer season near Talladega National Forest in Brent, Alabama. The site is situated at $32.903^{\prime} \mathrm{N}$, $87.250^{\prime} \mathrm{W}$, and at an elevation of $126 \mathrm{~m}$. Data were collected from 3 June to 15 July 2013. Our principle objectives were to measure continuous in situ aerosol volume distributions of the dry and particle-phase liquid water constituents over the 6-week time period of SOAS, and to identify chemical and thermodynamic controls on particle-phase liquid water content. This work contains a description and analysis of the instrument design, data reduction methods, and field measurement results based on measured RH; explores influences on ambient water content; and provides a method to estimate water content at different RH conditions. 
Table 1. Mean and quartiles of number concentration $N_{\text {conc }}$, relative humidity RH, temperature $T$, particle-phase water volume $V_{\mathrm{w}}$, semi-volatile volume Vsv lost during drying, volume of solutes $V_{\mathrm{d}}$, hygroscopicity parameters $\kappa_{\mathrm{vol}}, \kappa_{\mathrm{D} 1}$, and $\kappa_{\mathrm{D} 2}$, and volumetric growth factor $g f_{\text {vol }}$

\begin{tabular}{llrrrr}
\hline Parameter & Units & Mean & $\begin{array}{r}25 \% \\
\text { quartile }\end{array}$ & $\begin{array}{r}50 \% \\
\text { quartile }\end{array}$ & $\begin{array}{r}75 \% \\
\text { quartile }\end{array}$ \\
\hline$N_{\text {conc }}$ & $\mathrm{cm}^{-3}$ & 2629 & 1531 & 2155 & 3136 \\
$\mathrm{RH}$ & $\%$ & 68.94 & 59.95 & 70.85 & 77.10 \\
$T$ & ${ }^{\circ} \mathrm{C}$ & 27.48 & 24.85 & 26.73 & 30.06 \\
$V_{\mathrm{w}}$ & $\mu \mathrm{m}^{3} \mathrm{~cm}^{-3}$ & 4.00 & 1.34 & 2.88 & 4.86 \\
$V_{\mathrm{sv}}$ & $\mu^{3} \mathrm{~cm}^{-3}$ & 0.18 & -0.65 & 0.22 & 1.05 \\
$V_{\mathrm{d}}$ & $\mu \mathrm{m}^{3} \mathrm{~cm}^{-3}$ & 5.29 & 2.95 & 4.65 & 7.17 \\
$\kappa_{\mathrm{vol}}$ & dimensionless & 0.33 & 0.14 & 0.27 & 0.46 \\
$\kappa_{\mathrm{D} 1}$ & dimensionless & 0.47 & -0.11 & 0.13 & 0.78 \\
$\kappa_{\mathrm{D} 2}$ & dimensionless & 0.38 & 0.12 & 0.29 & 0.56 \\
$\mathrm{gf}_{\text {vol }}$ & dimensionless & 1.78 & 1.37 & 1.61 & 2.01 \\
\hline
\end{tabular}

\section{Methods}

\subsection{Instrument design}

A schematic of the instrument and experimental setup is presented in Fig. 1. Ambient air entered the instrument via a preconditioning inlet assembly consisting of a copper tube $(9.5 \mathrm{~mm} \mathrm{ID}, \sim 60 \mathrm{~cm}$ length) embedded in an aluminum block that was located $\sim 1 \mathrm{~m}$ above ground level under the roof of an open shed. The temperature of the copper tube could be stably controlled between $T_{\text {inlet }}-30 \pm 0.19^{\circ} \mathrm{C}$ and $T_{\text {inlet }}+50^{\circ} \mathrm{C}$ (TE Technology LC-061). An optional Nafion membrane water-to-gas humidifier (PermaPure MH 110-48) was used to condition the aerosol. Subsequently the aerosol passed through a charge neutralizer (Aerosol Dynamics Inc. model 100; Russell et al., 1996) holding four fresh ${ }^{210} \mathrm{Po}$ charge strips (NRD StaticMaster 2U500) with a nominal total activity of $2 \mathrm{mCi}$. The aerosol was routed through an equilibration section (not pictured) before entering a highflow differential mobility analyzer (DMA; Stolzenburg et al., 1998). The DMA sheath flow was controlled by a critical orifice (O'Keefe Controls Co., $9 \mathrm{~L} \mathrm{~min}^{-1}$ ) and configured in recirculation mode. Monodisperse aerosol exiting the DMA was counted by a condensation particle counter (CPC; TSI 3772) operated at $1 \mathrm{~L} \mathrm{~min}^{-1}$. Aerosol transit times were $2.5 \mathrm{~s}$ through the inlet loop, $6 \mathrm{~s}$ through the charge neutralizer, $5 \mathrm{~s}$ in the equilibration section between the Nafion humidifier and the DMA entrance, and 10.4 s through the DMA column. The residence of sample at the measurement $\mathrm{RH}$ is comparable to those used in other studies of hygroscopicity (cf. Table 1 in Duplissy et al., 2009).

The DMA was operated in scanning mobility particle sizer (SMPS) mode (Wang and Flagan, 1990). Negative voltage applied to the inner rod was held steady at $7 \mathrm{kV}$ for 60 to $190 \mathrm{~s}$, depending on the holding time of the present system state, and was then followed by an exponential decrease to $5 \mathrm{~V}$ over $300 \mathrm{~s}$. Mapping between the time-varying electric field and selected particle mobility was achieved using the method of Wang and Flagan (1990). Conversion between particle mobility and mobility diameter followed standard DMA theory (Knutson and Whitby, 1975). The diameter range was determined by the sheath flow rate and DMA dimensions $(60 \mathrm{~cm}$ tall, $11.6 \mathrm{~cm}$ ID outer cylinder, $10 \mathrm{~cm}$ OD collection rod) and spanned from $13 \mathrm{~nm}$ to $\sim 1.1 \mu \mathrm{m}$. The number size distribution was found via a standard inversion that accounts for the transmission of multiply charged particles using the method described in Petters et al. (2009a) with empirically determined adjustments accounting for particle transmission efficiencies that are described in detail in Sect. 2.2.

Relative humidity and temperature control of the DMA column were unchanged from previous versions of the instrument (Suda and Petters, 2013). Since the instrument was placed inside a well-ventilated shed, and since the objective was to track ambient temperatures, the neoprene insulation used by Suda and Petters (2013) was removed. Despite best efforts, the temperature inside the shed was slightly warmer than the outside, resulting in lower relative humidities inside the instrument relative to the values reported by the meteorology station. Both sheath and sample flows were optionally passed through Nafion humidifiers connected to a recirculating water bath. The water temperature determined the dew point temperature of the sheath and sample stream and was actively controlled by LabVIEW to match the ambient dew point temperature measured at the inlet. Temperature of the DMA column was measured using thermistors at the entrance, middle, and bottom of the instrument. Two aluminum sleeves with proportional-integral-derivative (PID) controlled thermoelectric heat exchangers that were mounted on the outside were used to reduce the standard deviation of the three thermistor temperatures to $0.21 \pm 0.16^{\circ} \mathrm{C}$. The nominal RH inside the instrument was computed from the average of the three thermistor temperatures and the flow rate weighted average of the measured sheath and sample dew point temperatures from the RH sensors embedded in the flows (HC2 Rotronics, Hygroclip, $\mathrm{RH}= \pm 0.8 \%$ accuracy). We have previously demonstrated (Suda and Petters, 2013) that this method of humidity control and measurement is sufficient for measuring aerosol hygroscopic growth and activity coefficients in tandem DMA studies at RH $<90 \%$.

The panels in Fig. 1 show three instrument states. In the unperturbed state, no humidity conditioning occurred to the sample prior to particle sizing. The temperature of the preconditioning copper tube and the DMA column temperatures equaled the temperature measured at the inlet. The Nafion humidifier was bypassed. The sheath flow was actively humidified to match the relative humidity of the sample stream. This configuration measured the particle size distribution with minimal perturbation to sample temperature and $\mathrm{RH}$.

In the dry instrument state, the temperature of the copper tube was chilled to $30^{\circ} \mathrm{C}$ below the inlet temperature (Fig. 1, panel 2). The temperature drop causes substances 

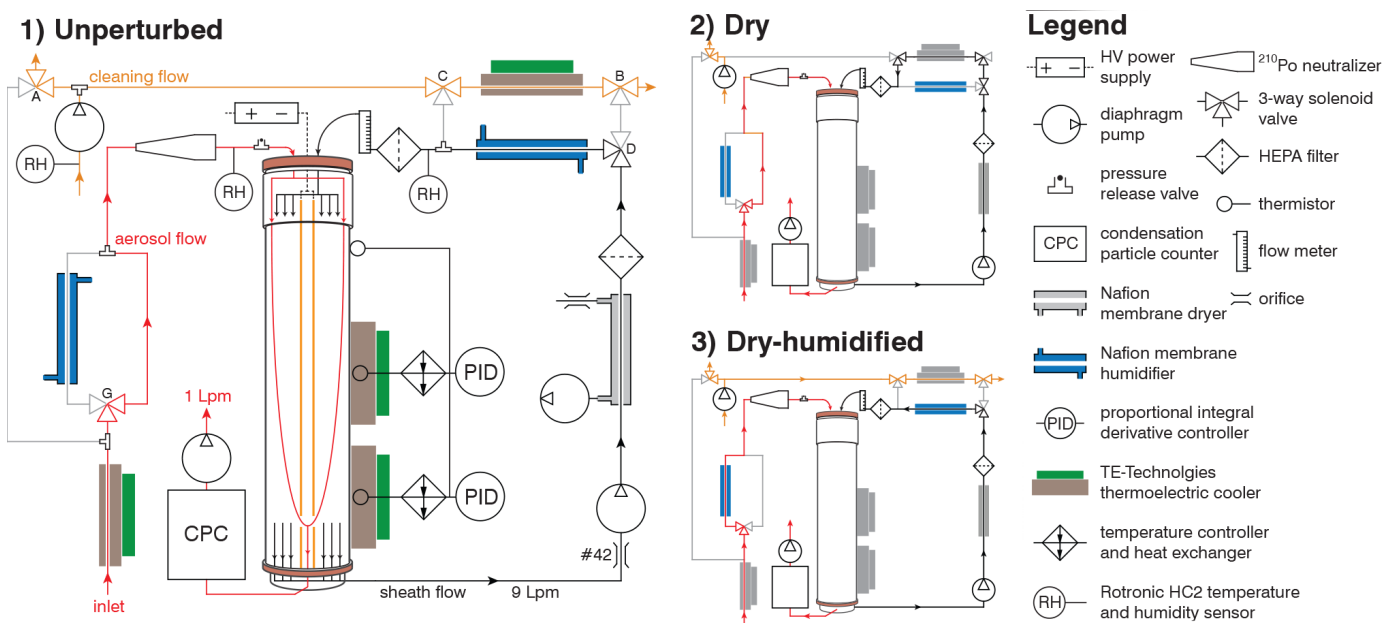

Figure 1. Instrument setup schematic. Red lines indicate the sample flow, black lines indicate the sheath flow, orange lines indicate the cleaning cycle flow, and grey lines indicate no flow. The column central to the figure is the differential mobility analyzer (DMA). Sheath and sample flows in the diagram are downward in the center and upward at the sides. The cleaning cycle is similar to the unperturbed cycle but with solenoid valve A toggled such that flushing air flows toward the actuated ball valve $\mathrm{G}$ and is split between the sample path to the CPC and the inlet, reversing the flow through the temperature-controlled preconditioner.

with dew point temperatures higher than the tubing temperature to condense onto the wall. Measurements of relative humidity downstream of the copper tube confirmed that the dew point of the sample was less than or equal to the temperature of the aluminum block the copper tube was embedded in. Upon exiting the copper tube, the sample flow warmed, resulting in a sharp drop in the water vapor saturation ratio. The sheath flow was conditioned in the same manner as the sample flow. This configuration measured the dry particle size distribution at $\mathrm{RH} \sim 10 \%$.

The dry-humidified state is similar to the unperturbed state (Fig. 1, panel 3). The difference is that the sample aerosol was dried using the same method as the dry instrument state. A temperature reduction of $30^{\circ} \mathrm{C}$ is expected to drop the saturation vapor pressure of typical semi-volatile organic compounds by 1-2 orders of magnitude (Booth et al., 2010). Compounds that become supersaturated will condense onto the wall or on the particles. Warming of the sample flow to the original temperature results in a lower saturation ratio of gas-phase organic species. Subsequent evaporation of now strongly subsaturated semi-volatile compounds may result in a net loss of organic mass from the particle. Note that equilibration time for semi-volatile compounds is longer than the transit time through the equipment $(\sim 11 \mathrm{~s}$ between inlet loop and DMA entrance). For example, the time required to evaporate to a diameter that is within $10 \%$ of the equilibrium size after a $30 \mathrm{~K}$ warming varies between 30 and $1000 \mathrm{~s}$ for $\alpha$ pinene SOA and aged SOA (cf. Fig. 2, Riipinen et al., 2010). We note that water-soluble organic gases may be affected differently than semi-volatile compounds. Water-soluble gases (e.g., glyoxal) have a high vapor pressure and a low saturation ratio. Due to their low saturation ratio they will not be removed by the cold trap by direct condensation onto the wall. However, some fractions may dissolve into the water condensate that forms as a result of the removal of water vapor. The dry-humidified state was designed to test whether the drying procedure resulted in net removal of particle volume.

The full duty cycle of the instrument was unperturbed, dry-humidified, and dry, followed by an automated cleaning cycle (not pictured in Fig. 1). During the cleaning cycle the temperature of the copper tube was warmed to $30^{\circ} \mathrm{C}$ above outside temperature and back-flushed with ambient air to remove water and other condensed substances from the tube. Verifying that the dew point temperatures measured before and after the copper tube were indistinguishable within experimental uncertainty ensured complete cleaning. Since the temperature of the copper tube had to be adjusted between the instrument states, there was a $160 \mathrm{~s}$ delay between the cleaning cycle and unperturbed state, $190 \mathrm{~s}$ between the unperturbed and dry-humidified states, and $60 \mathrm{~s}$ between the dry-humidified and dry states. A total of $600 \mathrm{~s}$ was allotted for the cleaning cycle. Approximately two unperturbed, dryhumidified, and dry size distributions were acquired per hour.

\subsection{Instrument performance}

Particle sizing accuracy was verified in the laboratory using polystyrene latex spheres (PSL; $102 \pm 3 \mathrm{~nm}$; Thermo Scientific, lot \#36489). The resulting measured size distribution was in agreement with the PSL size within the accuracy of the PSL spheres. Particle transmission efficiencies were quantified in the lab and the field using mobility selected effloresced ammonium sulfate particles. For these tests, particles were atomized from a stock solution $(99.9 \%$ pure 


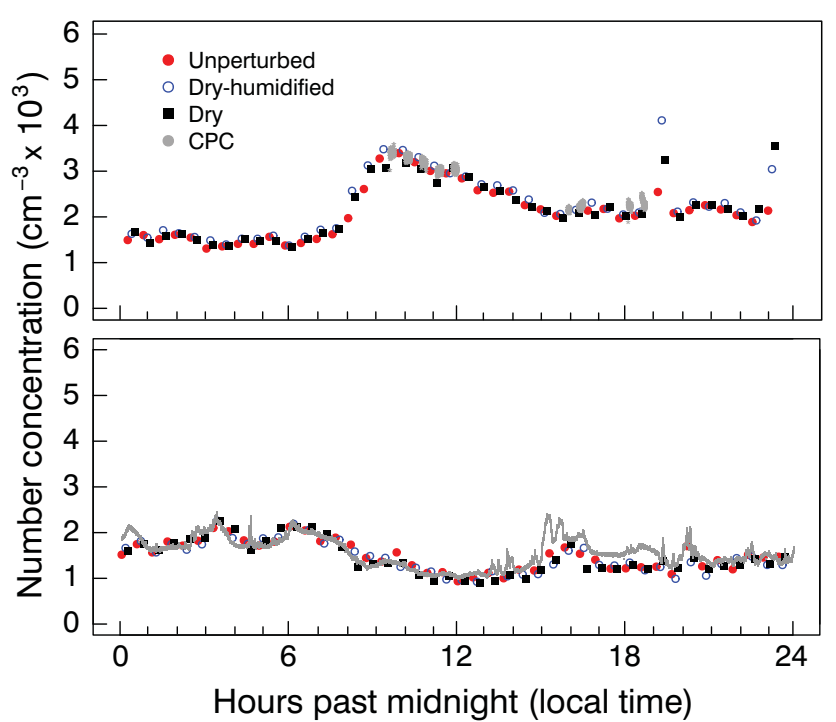

Figure 2. Top panel: example time series from 8 June. Symbols correspond to article number concentration obtained from integration over the size distribution (red: unperturbed; blue: dry-humidified; black: dry). Grey line corresponds to $1 \mathrm{~Hz}$ particle concentration from the CPC upstream of the SMPS with the inlet opened to ambient air during cleaning cycles. The plot shown here is a sample plot of the comparisons for 8 June. Bottom panel: example time series from 14 July. Symbols are the same as in the top panel. Grey line corresponds to $1 \mathrm{~Hz}$ particle concentration from a second $\mathrm{CPC}$ sampling side by side with the SMPS.

deionized water, $\sim 18.2 \mathrm{M} \Omega \mathrm{cm}$, Sigma-Aldrich) dried in a silica gel diffusion dryer (TSI 3062), charge-equilibrated, and size-selected by a second DMA (same origin and dimensions as the primary DMA, operated at 9:2 sheath-tomonodisperse flow ratio). Monodisperse aerosol was then routed to the SMPS and a second CPC (TSI 3771). Prior to these tests the two CPCs were intercompared sampling lab air side-by-side. Concentrations correlated well and the systematic offset between the instruments was $7.6 \%$, which is within the manufacturer's tolerance $( \pm 10 \%)$. Using this setup, the kernel function accounting for DMA transfer entering the inversion algorithm (Petters et al., 2009a) for the selected bin resolution (60 bins) was determined for a series of mobility sizes between 20 and $600 \mathrm{~nm}$. Reduced transmission efficiencies were encountered for $D<50 \mathrm{~nm}$, presumably due to diffusion losses. To account for reduced transmission, a diameter-dependent loss correction was included in the inversion matrix. Overall performance of the instrument was confirmed by comparing the DMA-integrated number concentration with the CPC-measured number concentration obtained either in simultaneously or sequentially with the size distribution scan. Concentrations from the integrated size distribution and the CPC agreed within $10 \%$.

The aforementioned procedure does not capture losses that may occur in the preconditioning inlet assembly. These losses were different for the unperturbed, dry-humidified, and dry state. To account for differential transmission between the different states, the unperturbed, dry-humidified, and dry states are multiplied by a constant factor of $1,1.2$, and 1.12 , respectively, to match the concentrations of a colocated CPC that was available prior to the start of the campaign (27-29 May) as well as 3-15 July. Between 3 June and 3 July, instrument performance was validated by disconnecting the CPC from the DMA during several cleaning cycles. After 3 July the CPC sample flow was reduced to $0.5 \mathrm{~L} \mathrm{~min}^{-1}$ to accommodate $0.5 \mathrm{~L} \mathrm{~min}^{-1}$ flow for a cloud condensation nuclei counter added to the setup. Thus the total flow through the DMA was unchanged. Number distribution readings from the CPC were adjusted accordingly to account for the reduced number of particles counted. The regular system performance checks were also carried out after the change. No degradation of instrument performance was observed. Figure 2 shows example time series of particle number concentration observed with the SMPS and condensation particle counters. The figure shows that there is generally satisfactory agreement between SMPS and CPC derived concentrations, although there are some time periods when the SMPS undercounted relative to the CPC (e.g., Fig. 2 bottom panel $15-20 \mathrm{~h}$ ). The reasons for this are not entirely clear, but undercounting occurs preferentially when fine-mode aerosols are present. This indicates that transmission correction for particles with $D<50 \mathrm{~nm}$ may not fully account for the combined losses in the inlet assembly and the DMA column. We do not believe that these deviations are of concern since aerosol volume is most sensitive to accumulation mode sizes, and thus the error in volume introduced by these deviations is small.

\subsection{Data reduction}

The volume of water associated with the aerosol is described using the hygroscopicity model of Petters and Kreidenweis (2007) and Kreidenweis et al. (2008):

$V_{\mathrm{w}}=V_{\mathrm{d}} \kappa \frac{a_{\mathrm{w}}}{1-a_{\mathrm{w}}}$,

where $a_{\mathrm{w}}$ is the water activity, $V_{\mathrm{w}}$ and $V_{\mathrm{d}}$ are the volume of water and dry aerosol components, and $\kappa$ is the hygroscopicity parameter. In general $\kappa$ may vary with water activity and depends on particle chemical composition. For a particle composed of multiple components, the particle's $\kappa$ can be computed from the volume-weighted mixture of its dry components,

$\kappa=\sum \varepsilon_{i} \kappa_{i}$,

where $\varepsilon_{i}$ and $\kappa_{i}$ are the volume fraction and hygroscopicity parameter of the $i$ th component comprising the particle. Water activity and $\mathrm{RH}$ are related via

$a_{\mathrm{w}}=\mathrm{RH} \exp \left(\frac{4 \sigma_{\mathrm{w}} M_{\mathrm{w}}}{\rho_{\mathrm{w}} R T D}\right)^{-1}$, 
where $\sigma_{\mathrm{w}}, M_{\mathrm{w}}$, and $\rho_{\mathrm{w}}$ represent the surface tension, molecular weight, and density of water, respectively; $T$ is the absolute temperature; $R$ is the ideal gas constant; $D$ is the humidified particle diameter; and RH is the fractional relative humidity. Two hygroscopic growth factors can be defined:

$g f_{\mathrm{vol}}=\frac{V_{\mathrm{w}}+V_{\mathrm{dry}}}{V_{\text {dry }}}$ and $\mathrm{gf}_{\mathrm{D}}=\frac{D}{D_{\mathrm{d}}}$,

where $g f_{\mathrm{vol}}$ and $g f_{\mathrm{D}}$ are the volume- and diameter-based growth factors, and $D_{\mathrm{d}}$ is the dry particle diameter. The dry particle composition can be conceptually divided into a lowvolatility (lv) and a semi-volatile (sv) fraction. The component parameter sets are $\left\{\varepsilon_{\mathrm{lv}}, \kappa_{\mathrm{lv}}, V_{\mathrm{w}, \mathrm{lv}}\right.$ and $\left.V_{\mathrm{d}, \mathrm{lv}}\right\}$ and $\left\{\varepsilon_{\mathrm{sv}}\right.$, $\kappa_{\mathrm{sv}}, V_{\mathrm{w}, \mathrm{sv}}$ and $\left.V_{\mathrm{d}, \mathrm{sv}}\right\}$, respectively. Assuming that volumes are additive (see Sect. 2.4 for further discussion), the total volumes of water and dry components are $V_{\mathrm{w}}=V_{\mathrm{w}, \mathrm{lv}}+V_{\mathrm{w}, \mathrm{sv}}$ and $V_{\mathrm{d}}=V_{\mathrm{d}, \mathrm{lv}}+V_{\mathrm{d}, \mathrm{sv}}$.

Aerosol water and aerosol semi-volatile volumes are quantified using the measured aerosol volume of three consecutively measured instrument states: unperturbed, dryhumidified, and dry. The measured volumes of the three states correspond to

$$
\begin{aligned}
& V_{\text {unperturbed }}=V_{\mathrm{w}, \mathrm{lv}}+V_{\mathrm{w}, \mathrm{sv}}+V_{\mathrm{d}, \mathrm{lv}}+V_{\mathrm{d}, \mathrm{sv}} \\
& V_{\mathrm{dry}}=V_{\mathrm{d}, \mathrm{lv}} \\
& V_{\text {dry-humidified }}=V_{\mathrm{w}, \mathrm{lv}}+V_{\mathrm{d}, \mathrm{lv}},
\end{aligned}
$$

where $V_{\text {unperturbed }}, V_{\text {dry }}$, and $V_{\text {dry-humidified }}$ are the total particle volumes measured for each instrument state, again assuming that volumes are additive. The semi-volatile volumes in Eq. (5) are operationally defined to correspond to the amount that was lost during the drying procedure. Consequently, aerosol water volume associated with the lowvolatility material is

$V_{\mathrm{w}, \text { lv }}=V_{\text {dry-humidified }}-V_{\text {dry }}$.

As will be discussed in Sect. 4, the contribution of $V_{\mathrm{d} \text {,sv }}$ to $V_{\mathrm{w}}$ was not discernible. The semi-volatile volume lost during drying is

$V_{\mathrm{sv}, \text { instrument }}=V_{\text {unperturbed }}-V_{\text {dry-humidified }}$.

We note that the instrument defined loss of $V_{\mathrm{sv} \text {,instrument }}$ implies a loss of water that was hygroscopically bound in the particle. The amount of water associated with the semivolatile fraction can be determined by combining Eq. (7) with Eqs. (1) and (2) and solving for the amount of dry semivolatile volume lost,

$V_{\mathrm{d}, \mathrm{sv}}=V_{\mathrm{sv}, \text { instrument }} \frac{1-a_{\mathrm{w}}}{1-a_{\mathrm{w}}+\kappa_{\mathrm{sv}} a_{\mathrm{w}}}$.

Equation (8) demonstrates that if $\kappa_{\mathrm{sv}}=0$ (corresponding to a hypothetical nonhygroscopic material that is lost during

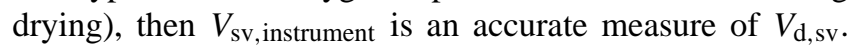

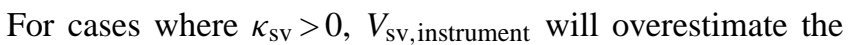
amount of semi-volatile material lost during drying. Equation (8) can be used to estimate the magnitude of this effect.

Volumes entering Eqs. (6) and (7) are derived from the size distribution data. Volume distributions were calculated from the number size distributions assuming particle sphericity following Seinfeld and Pandis (2006). Figure 3 shows example histograms of the inverted 60-bin representation of the number and volume size distribution. The data show that the size distribution is bimodal, with mode diameters $D_{\mathrm{p} 1}$ $\sim 0.06 \mu \mathrm{m}$ and $D_{\mathrm{p} 2} \sim 0.2 \mu \mathrm{m}$. The relative contributions of number and volume to the ratio of mode 1 to 2 are $\sim 10: 1$ and $\sim 1: 2$, respectively. Low number concentrations result in poor counting statistics, leading to the apparent noisiness of the volume distribution histograms in the larger size mode. A single false count in the largest diameter bins can significantly bias the total volume derived from the spectra. False counts sometimes arise due to arcing in the DMA column. Arcing occurs at high relative humidity and high electric potential, leading to a breakdown of the electric field in the column. This enables transmission of smaller particles that are falsely sized in the large bins. These particles would appear as a peak at $D \sim 1 \mu \mathrm{m}$ (not seen in Fig. 3).

To filter out possible contributions from arcing, reduce the noisiness from low counting statistics, and identify the mode diameters in each scan, lognormal distribution functions (Hatch and Choate, 1929) are fitted to the distribution data. A nonlinear least-squares fitting routine is used to minimize the residual between the data and the distribution function. Artifacts from rogue counts at high diameters are filtered since a third mode is not allowed. Distribution functions are fit to both the number and volume distributions separately. Example fits to the histograms are superimposed in Fig. 3. To test the efficacy of the fits to represent the data, the fit- and data-integrated moments were compared. For each distribution, the relative difference between integrated number concentration from the data and the fit was $1.4 \pm 5 \%$, where $1.4 \%$ denotes the average error and $\pm 5 \%$ the fit-to-fit variability of the error. Similarly, the statistics for the integrated volume are $1.6 \% \pm 5.3 \%$. The variability in the data greatly exceeds any artificial error introduced by the two-mode parameterization, indicating that the twomode parameterization is appropriate to model the size distribution. Measured volume concentrations were correlated with mass concentrations from a colocated tapered element oscillating microbalance (Patashnick and Rupprecht, 1991; see Supplement). The offset between these measurements is broadly consistent with an aerosol density of $1.5 \mathrm{~g} \mathrm{~cm}^{-3}$, a value that is reasonable for the measured aerosol chemical composition. Note that the average number and volume fraction of particles with $D<50 \mathrm{~nm}$ to smaller mode is 30.6 and $19 \%$, respectively. For those sizes, instrument performance is degraded due to diffusional losses. However, since the contribution of $D<50 \mathrm{~nm}$ particles is less than $50 \%$, and since the potential error is likely serious only for $D<30 \mathrm{~nm}$, we 


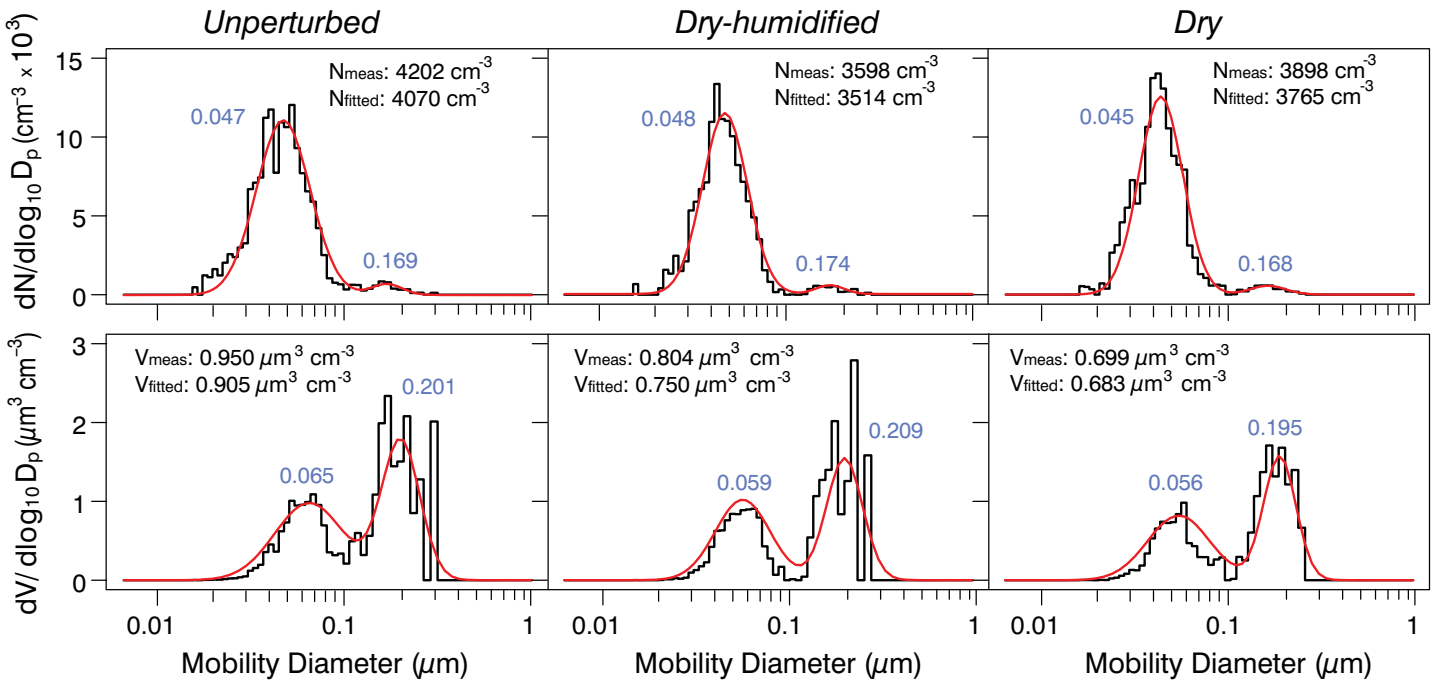

Figure 3. Example data from 5 July 2013. Histograms represent measured 60-bin representation of the number size distribution (top row) and derived volume size distributions (bottom row) for the unperturbed (left panels), dry-humidified (middle panels), and dry (right panels) instrument states. Red lines correspond to a bimodal lognormal distribution fitted to the data. Data-derived and fit-derived number and volume concentrations are provided in the legend. Blue numbers indicate the mode diameters obtained from the fit to the distributions.

do not expect that diffusional losses affect the fit-determined mode diameter.

The fitted volumes $V_{\text {unperturbed }}$ and $V_{\text {dry }}$ are entered into Eq. (6) in order to find $V_{\mathrm{w}}$. Furthermore, $V_{\text {dry }}$ defines $V_{\mathrm{d}}$ in Eq. (1). Calculations were also performed using the data distributions directly, and summary statistics are provided in the online supplement. For these calculations, we assume $a_{\mathrm{w}}$ is equivalent to RH measured by the instrument, and the implications of this assumption are discussed later on in Sect. 2.4.

Alternatively, growth factors are defined by calculating the ratio of the shift in the mode diameters from the lognormal fit between $V_{\text {unperturbed }}$ and $V_{\text {dry }}$ :

$\mathrm{gf}_{i}=\frac{D_{\text {pgi,unperturbed }}}{D_{\text {pgi,dry }}}$

where $\mathrm{gf}_{i}$ is the diameter growth factor of the $i$ th lognormal mode and $D_{\text {pgi,unperturbed }}$ and $D_{\text {pgi,dry }}$ are the fit-returned mode diameters of the $i$ th lognormal mode for the sequential unperturbed and dry measurement cycles. Conversion from $\mathrm{RH}$ to water activity is performed using Eq. (3) and with $D_{\text {pgi,unperturbed }}$ as the particle diameter. The resulting diameter growth factors can be used to define $\kappa$ values that characterize the hygroscopicity of the individual modes:

$\kappa_{D i}=\left(\mathrm{gf}_{i}^{3}-1\right)\left(1-a_{\mathrm{w}}\right) a_{\mathrm{w}}^{-1}$,

where $\kappa_{D i}$ is the diameter-based hygroscopicity parameter for the $i$ th lognormal mode.

The fitted volumes $V_{\text {unperturbed, }}$ and $V_{\text {dry-humidified }}$ enter

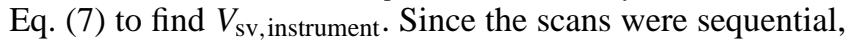
relative humidity was not necessarily the same between the two scans. To account for $\mathrm{RH}$ variations from the target value the $V_{\text {dry-humidified }}$ volume was empirically corrected to the $\mathrm{RH}$ corresponding to the unperturbed cycle as recommended by Gysel et al. (2009). In our case, the correction is performed as follows. First, $\kappa_{\mathrm{vol}, \text { dry-humidified }}$ is determined from $V_{\text {dry-humidified }}$ and $V_{\text {dry }}$ using Eq. (1) and $\mathrm{RH}_{\text {dry-humidified, }}$, and second, we obtain the corrected state using

$V_{\text {dry-humidified,corrected }}=V_{\text {dry }} \kappa_{\mathrm{vol}} \frac{\mathrm{RH}_{\text {unperturbed }}}{1-\mathrm{RH}_{\text {unperturbed }}}+V_{\text {dry }}$,

where $V_{\text {dry-humidified,corrected }}$ is the corrected volume for the dry-humidified state, $\kappa_{\mathrm{vol}}$ is the size distribution integrated volume based hygroscopicity parameter computed from Eq. (1), and $\mathrm{RH}_{\text {unperturbed }}$ is the average $\mathrm{RH}$ measured during the unperturbed state.

\subsection{Sources of uncertainty}

Since $\mathrm{RH}_{\text {unperturbed }}$ was slightly lower than that measured at the meteorological station due to slight heating of the shed, the reported water contents represent a lower estimate. The relative difference between the two RH sensors, computed as $\left(\mathrm{RH}_{\text {met }}-\mathrm{RH}_{\text {shed }}\right) / \mathrm{RH}_{\text {met }}$, was $15 \%$. Equation (11) can be used to estimate the corrected water content at conditions deviating from instrument conditions.

The DMA measures mobility diameter, which for spherical particles is equal to the volume equivalent diameter. During the unperturbed and dry-humidified state, particles that contain water will likely have a nearly spherical shape because water preferentially adsorbs at the corners and edges of the particle (Mikhailov et al., 2004). However, some particles may have a crystalline structure when dried. Particle shape irregularities increase the drag inside the DMA and result in a 
larger electric mobility diameter measured. Compounds with a cubic structure, for example, have a shape factor of 1.08 (e.g., Kelly and McMurry, 1992). Gysel et al. (2002) calculated that the relation between the volume equivalent diameter and the mobility diameter of a cubic particle is 0.96 , which indicates a $4 \%$ overestimate of particle diameter by the DMA for cubic particles. As a result, the volume distribution calculated from the mobility diameters of irregularly shaped particles during the dry state may be overestimated, which would result in an underestimate of water content when we difference the dry-humidified and dry states.

The calculations also assume volume additivity, i.e., that aerosol species volumes are independent of solution concentration and of species mixing fractions. Detailed studies of water activity for inorganic compounds show that the excess volume of mixing can be large for some systems, particularly at low water content (Clegg et al., 1998; Wexler and Clegg, 2002). However, other studies find that volume additivity holds, although this may be due to the cancellation of excess volumes (Stokes and Robinson, 1966). Mikhailov et al. (2004) found volume additivity to be a safe assumption for aerosols composed of proteins and salts for which the individual densities and behavior in solution were known. In the absence of detailed knowledge of composition and the component behavior in solution, as is the case with ambient aerosol, volume additivity has typically been assumed (Dick et al., 2000; Speer et al., 2003). Dick et al. (2000) constrained their results with the calculation that for simple aqueous inorganic solutions volume additivity misestimates particlephase liquid water by $-7 \%$ for $\mathrm{H}_{2} \mathrm{SO}_{4}$ at $\mathrm{RH}=90 \%$ and by $<5 \%$ for deliquesced $\mathrm{NH}_{4} \mathrm{HSO}_{4},\left(\mathrm{NH}_{4}\right)_{3} \mathrm{H}\left(\mathrm{SO}_{4}\right)_{2}$, and $\left(\mathrm{NH}_{4}\right)_{2} \mathrm{SO}_{4}$, thus providing an estimate of error for different ammonium-to-sulfate ratios for the inorganic fraction of ambient aerosols. In summary, we conclude that the assumption of volume additivity may introduce a small error into our calculations when molecular interactions in the solution deviate from the pure components.

Since multiple sizes contribute to the fitted volumes, the conversion from instrument RH (Sect. 2.1) to $a_{\mathrm{w}}$ via Eq. (3) is not straightforward. We therefore assume $a_{\mathrm{w}}$ is equivalent to RH averaged over the scan to compute $\kappa_{\mathrm{vol}}$. The expected difference between RH and water activity are between 0.01 and 0.02 in absolute units (e.g., Tang, 1996) and will result an RH-dependent overestimate in $\kappa_{\mathrm{vol}}$ ranging from 4 to $11 \%$.

Changes in aerosol solution from stable to metastable conditions during the dry-humidified state can also introduce errors into the calculations of water volume. Inside the Nafion tube during the dry-humidified state, the RH approaches $\sim 100 \%$ at the temperature that approximates the dew point temperature of the outside air. Inside the Nafion humidifier during the dry-humidified state, the RH approaches $\sim 100 \%$ at the temperature that approximates the dew point temperature of the outside air. Thus most particles that can deliquesce at subsaturated relative humidity will contain water exiting the Nafion. Particles may or may not effloresce prior to entering the DMA. If $V_{\text {dry-humidified }}$ exceeds $V_{\text {unperturbed, }}$, it may be possible that a sufficiently large volume of water was added by the deliquescence of water on particles that were effloresced under unperturbed conditions.

Some compounds do not effloresce and thus may retain water at low RH. In that case the measured $V_{\text {dry }}$ will be overestimated and the instrumented-inferred $\mathrm{gf}_{\mathrm{vol}}$ and $\kappa_{\mathrm{vol}}$ will be biased low. The relative error in the inferred $\kappa_{\mathrm{vol}}$ at $a_{\mathrm{w}}=0.12$, for example, is $e_{\kappa}=\left(\kappa_{\mathrm{vol}, \mathrm{dry}}-\kappa_{\mathrm{vol}, 0.12}\right) / \kappa_{\mathrm{vol}, \mathrm{dry}}$, where $\kappa_{\mathrm{vol}, \text { dry }}$ is the true hygroscopicity and $\kappa_{\mathrm{vol}, 0.12}$ is the hygroscopicity one would calculate if particle-bound water was present at $a_{\mathrm{w}}=0.12$. Equation (1) can be used to estimate the magnitude of the particle-bound water at $a_{\mathrm{w}}=0.12$, assuming that $\kappa$ is invariant with $a_{\mathrm{w}}$. From that the total particle volume $\left(V_{\mathrm{w}}+V_{\mathrm{d}}\right)$ can be computed. If the total volume is mistakenly assumed to equal the dry volume, a $\kappa_{\mathrm{vol}, 0.12}$ can be computed. The estimated error is independent of $a_{\mathrm{w}}$ and scales with $\kappa_{\mathrm{vol}, \text { dry }}$. For $\kappa_{\mathrm{vol}, \text { dry }}=0.01$ and $\kappa_{\mathrm{vol}, \text { dry }}=0.6$, the error is $e_{\kappa}=-0.1 \%$ and $e_{\kappa}=-7.6 \%$, respectively. We also note that the dry instrument state corresponds to $\mathrm{RH}=12.5 \% \pm 2.3 \%$, where $2.3 \%$ denotes the variability of the RH in absolute units at the dry state throughout the campaign.

Although losses of semi-volatile compounds during drying are expected, the total amount lost unlikely corresponds to what would be expected from thermodynamic equilibrium. Several reasons are listed here. First, fast kinetics for aerosol dissolution are required. However, this may not be the case if the initial RH is low, as the aerosol becomes viscous and formation of a homogenous liquid phase may be slow (Vaden et al., 2011; Renbaum-Wolff et al., 2013). Second, evaporation rates must be fast enough to remove semi-volatiles in the inlet even though evaporation rates may be slow (Bilde et al., 2003). Succinic acid, for example, has been measured to have an evaporation rate of $2.76 \mathrm{~nm} \mathrm{~s}^{-1}$ at $299.8 \mathrm{~K}$ and $64.1 \% \mathrm{RH}$ (Koponen et al., 2007). The residence time of the preconditioning inlet may not be adequate to capture full evaporation of succinic acid. Third, the phase state of the particles after drying is uncertain. Sub-cooled liquid vapor pressure may be up to 3 orders of magnitude higher than solid vapor pressure (Booth et al., 2010). Since partitioning between gas and particle phase is dependent on the saturation vapor pressure of the organic compound in the liquid state (Pankow, 1994), semivolatile content may be underestimated if particles are in the solid state after drying. However, water in the organic phase could reduce organic equilibrium partial pressure according to Raoult's law (Pankow and Chang, 2008), though this effect did not play a strong role on $\alpha$-pinene SOA formation (Prisle et al., 2010). Detailed studies with proxy systems are needed to quantify the amount removed as a function of compound volatility in the context of particle phase/viscosity/diffusion and nonideal solution effects. Therefore, the tests with the preconditioning inlet only test whether the selected drying procedure lead to loss of material during SOAS and is not intended to be used as a measure of the semi-volatile fraction. 


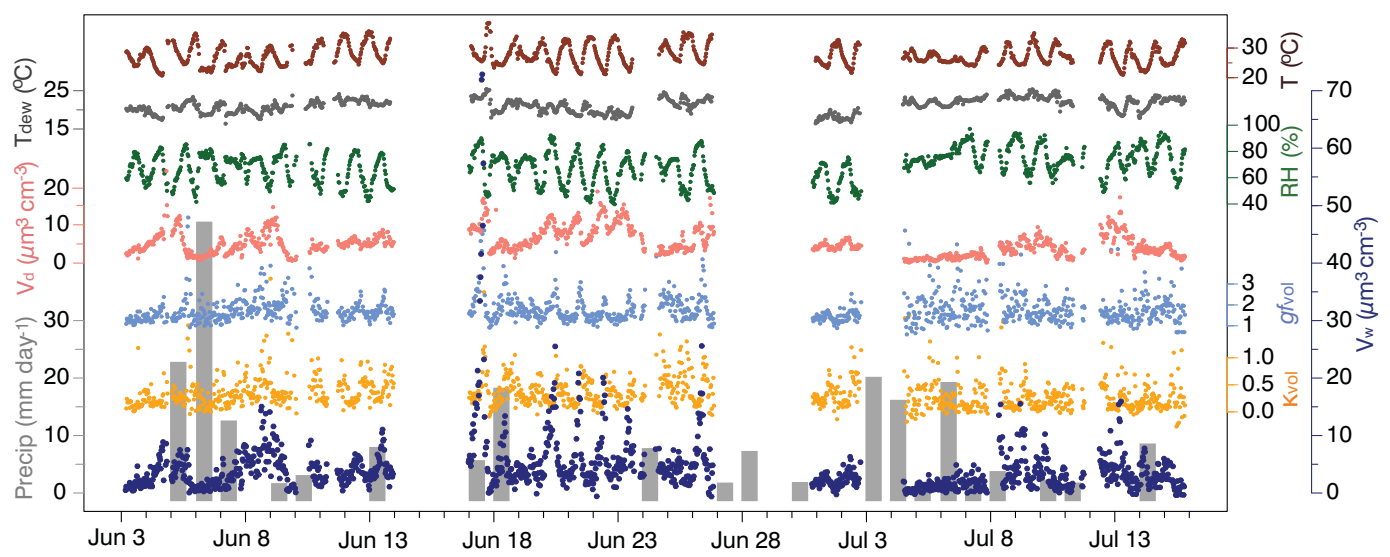

Figure 4. From top to bottom in foreground of figure: time series of $(1)$ temperature $\left(T,{ }^{\circ} \mathrm{C}\right)$ in brown, $(2)$ dew point temperature $\left(T_{\mathrm{dew}},{ }^{\circ} \mathrm{C}\right)$ in dark grey, (3) relative humidity $(\mathrm{RH}, \%)$ in green, (4) aerosol dry volume $\left(V_{\mathrm{d}}, \mu \mathrm{m}^{3} \mathrm{~cm}^{-3}\right)$ in pink, (5) volumetric growth factor $\left(\mathrm{gf}_{\mathrm{vol}}\right.$, dimensionless) in light blue, (6) volumetric $\kappa\left(\kappa_{\mathrm{vol}}\right.$, dimensionless) in orange, and (7) particle-phase liquid water $\left(V_{\mathrm{w}}, \mu \mathrm{m}^{3} \mathrm{~cm}^{-3}\right)$ in dark blue. Precipitation (Precip, $\mathrm{mm} \mathrm{day}^{-1}$ ) is shown in grey bars at the bottom of the plot. All of the data except for precipitation were recorded by the SMPS. Gaps in the data indicate periods when the instrument was not operating. Precipitation data are from the ARA SEARCH network.

\subsection{Chemical composition}

$\mathrm{PM}_{2.5}$ or $\mathrm{PM}_{1}$ water-soluble ions were measured by a particle-into-liquid sampler coupled with an ion chromatograph (PILS-IC; Metrohm 761 Compact IC). Similar setups are described in previous field studies (Orsini et al., 2003; Hecobian et al., 2010; Liu et al., 2012). A Metrosep A Supp 5 anion column and a C 4150 cation column (Metrohm USA, Riverside FL) were used to separate PILS liquid sample anions sulfate, nitrate, chloride, oxalate, acetate, formate and cations ammonium, sodium, potassium, calcium, and magnesium with a $20 \mathrm{~min}$ duty cycle. Water soluble organic carbon (WSOC) was measured by coupling the PILS with a total carbon analyzer (TOC, Model 900, GE Analytical Instruments; Boulder, CO). The TOC analyzer was operated in normal mode with a 6 min duty cycle. The PILS sample air flow rate was $16.8 \pm 0.35 \mathrm{~L} \mathrm{~min}^{-1}$ and URG cyclone inlets provided PM cut sizes of $\mathrm{PM}_{2.5}$ for the first half of field study ( 1 to 22 June) and $\mathrm{PM}_{1}$ for the latter half (23 June to 15 July). Honeycomb acid (phosphoric acid) and base (sodium carbonate)-coated denuders remove interfering gases. Water-soluble organic matter (WSOM) was then estimated from WSOC measurements using a conversion factor of 2.1 (Turpin and Lim, 2001). The sample inlet was $\sim 7 \mathrm{~m}$ a.g.l. and $\sim 4 \mathrm{~m}$ long. The inlet line was insulated inside a trailer (typical indoor $T$ was $25^{\circ} \mathrm{C}$ ) and less than $1 \mathrm{~m}$ in length to minimize possible changes in aerosol composition prior to measurement. The trailer was located adjacent to the shed housing the SMPS system. Periodic $1 \mathrm{~h}$ blank measurements were made every day by placing a HEPA filter (Pall Corporation) on the cyclone inlet. All data were blankcorrected.

\section{Results}

Figure 4 provides a time series of the measured data for the 6 weeks of data collection. A campaign-based statistical summary of selected parameters encountered in the instrument is summarized in Tables 1 and 2. Temperatures measured by the instrument typically fluctuated between $\sim 24{ }^{\circ} \mathrm{C}$ during nighttime and $\sim 30^{\circ} \mathrm{C}$ during daytime. Minor fluctuations in the dew point temperature $\left(T_{\mathrm{dew}}\right)$ indicate that the diel cycle of RH was driven mostly by temperature variations highest at low temperatures and lowest at high temperatures. Daily fluctuations for RH within the instrument were typically within the range of 60 to $77 \%$. Periods of heavy rainfall included 5-7 and 18 June and 3-6 July. The highest amount of precipitation for a single day was $45.8 \mathrm{~mm}$ on 6 June. Periods with little to no rainfall included $8,11-12,14-16,19$ 22 , and 25-26 June and 9-12 July. Periods with noticeably high amounts of rainfall, such as 5 and 6 June, resulted in low levels of dry $\left(V_{\mathrm{d}}\right)$ and water aerosol $\left(V_{\mathrm{w}}\right)$ volume. During periods with no rainfall, such as the days between 19 and 22 June, dry particle volume steadily increased, presumably due to the lack of an efficient aerosol sink.

Statistics of the campaign-average bimodal distributions of number concentration, surface area, and volume for the three-instrument inlet states are summarized in Table 2. A graphical interpretation of Table 2 is provided in Fig. 5. Average number concentrations were $\sim 2300$ and $500 \mathrm{~cm}^{-3}$ for the smaller and larger diameter mode, respectively. Surface area distributions are higher for the unperturbed and dryhumidified states than for the dry state due to the additional water uptake. For the smaller diameter mode, surface areas average at $54.0 \mu \mathrm{m}^{2} \mathrm{~cm}^{-3}$ for both the unperturbed and dry-humidified states, and $54.4 \mu \mathrm{m}^{2} \mathrm{~cm}^{-3}$ for the dry state, 
Table 2. Parameters describing two-mode distributions of number concentration, surface area, and volume for the unperturbed ( $\left.C_{\text {unperturbed }, i}\right)$, dry-humidified $\left(C_{\mathrm{dry} \text {-humidified, } i}\right)$, and dry states $\left(C_{\mathrm{dry}, i}\right)$.

\begin{tabular}{llrrrrrr}
\hline Parameter & Units & \multicolumn{2}{c}{ Number $N$} & \multicolumn{2}{c}{ Surface $S$} & \multicolumn{2}{c}{ Volume $V$} \\
\hline Mode & & 1 & 2 & 1 & 2 & 1 & 2 \\
$C_{\text {unperturbed }, i}$ & $\mathrm{~cm}^{-3}$ & 2254 & 507 & 54.0 & 130 & 2.20 & 6.50 \\
gmd $_{\text {unperturbed }, i}$ & $\mu \mathrm{m}$ & 0.099 & 0.24 & 0.11 & 0.25 & 0.16 & 0.32 \\
gsd $_{\text {unperturbed, } i}$ & & 1.54 & 1.43 & 1.54 & 1.43 & 1.54 & 1.43 \\
Mode & & 1 & 2 & 1 & 2 & 1 & 2 \\
$C_{\text {dry-humidified }, i}$ & $\mathrm{~cm}^{-3}$ & 2238 & 511 & 54.0 & 127 & 2.18 & 6.93 \\
gmd dry-humidified, $i$ & $\mu \mathrm{m}$ & 0.11 & 0.23 & 0.12 & 0.25 & 0.16 & 0.35 \\
gsd dry-humidified,$i$ & 1.49 & 1.49 & 1.5 & 1.49 & 1.5 & 1.49 & 1.5 \\
Mode $_{C_{\text {dry }} i}$ & & 1 & 2 & 1 & 2 & 1 & 2 \\
gmd $_{\text {dry }, i}$ & $\mathrm{~cm}^{-3}$ & 2355 & 403 & 54.4 & 95 & 1.49 & 3.87 \\
gsd $_{\text {dry }, i}$ & $\mu \mathrm{m}$ & 0.096 & 0.2 & 0.10 & 0.22 & 0.14 & 0.28 \\
\hline
\end{tabular}

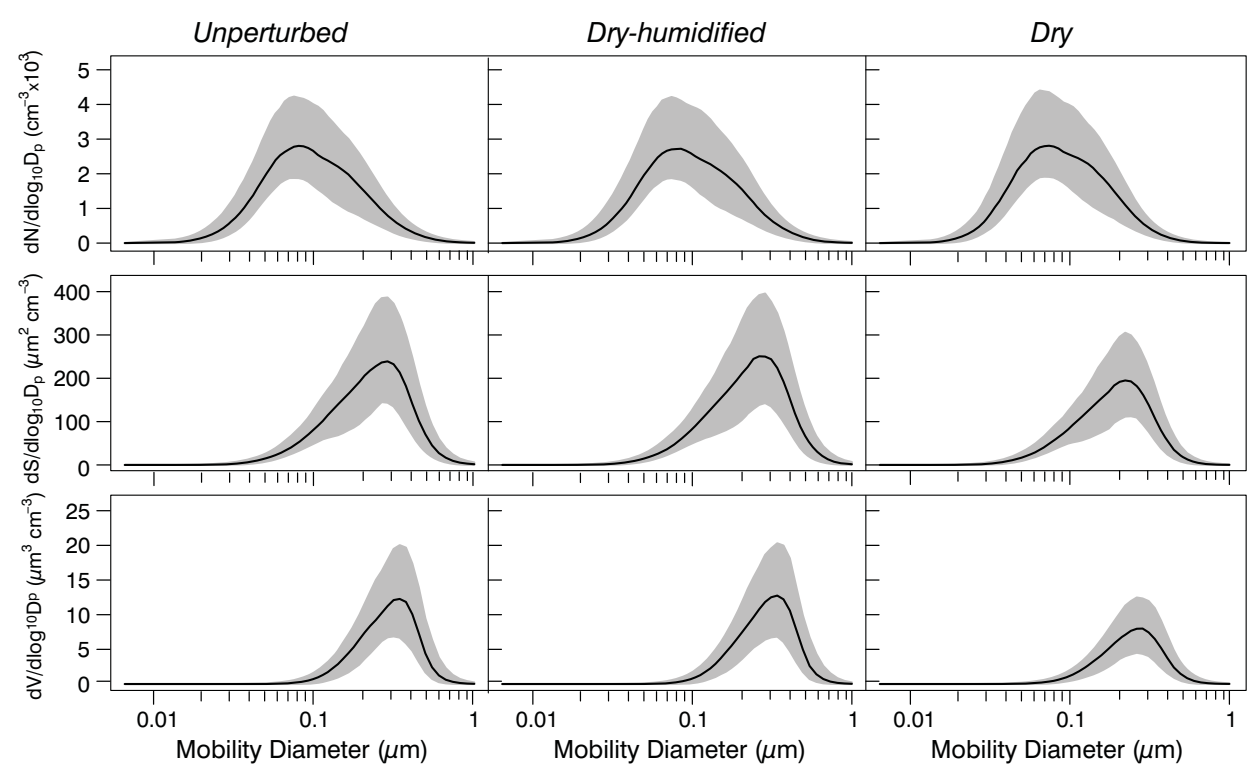

Figure 5. Summary number concentration (top row), surface area (middle row), and volume (bottom row) distributions for 3 June to 15 July 2013. The left panels indicate the unperturbed state, the middle panels the dry-humidified state, and the right panels the dry state. The central black lines show the median distribution, and the grey-shaded regions represent the interquartile range.

while for the larger mode, the averages are 130, 127, and $95 \mu \mathrm{m}^{2} \mathrm{~cm}^{-3}$ for the unperturbed, dry-humidified, and dry states, respectively. This indicates that water uptake increases the aerosol surface area by $33.7 \%$ for the large diameter mode, while the effect for the small diameter mode is not observed, suggesting that the smaller mode is less hygroscopic. (Note that the surface area of the small mode nominally shrinks by $0.07 \%$ upon humidification. Possible reasons are noise in the measurement and that some fraction of the particles is picked up in mode 1 for the "dry" fit and mode 2 for the humidified fit.) Similarly, the volume distributions for the unperturbed and dry-humidified state are both larger than the distribution for the dry state. Volume averages are 2.20,
2.18, and $1.49 \mu^{3} \mathrm{~cm}^{-3}$ for the smaller diameter mode and $6.50,6.93$, and $3.87 \mu \mathrm{m}^{3} \mathrm{~cm}^{-3}$ for the larger diameter mode, for the unperturbed, dry-humidified, and dry states, respectively. The observed size distribution statistics are consistent with previous measurements of accumulation-mode remote continental aerosol size distributions (Jaenicke, 1993; Martin et al., 2010; Levin et al., 2012). Notably, small particle events indicative of nucleation (Levin et al., 2012) were not observed during the campaign. Number and volume concentrations were significantly higher during SOAS than during the Amazonian Aerosol Characterization Experiment (Martin et al., 2010), suggesting anthropogenic influence, likely from sulfates, at the SOAS site (Carlton and Turpin, 2013). 


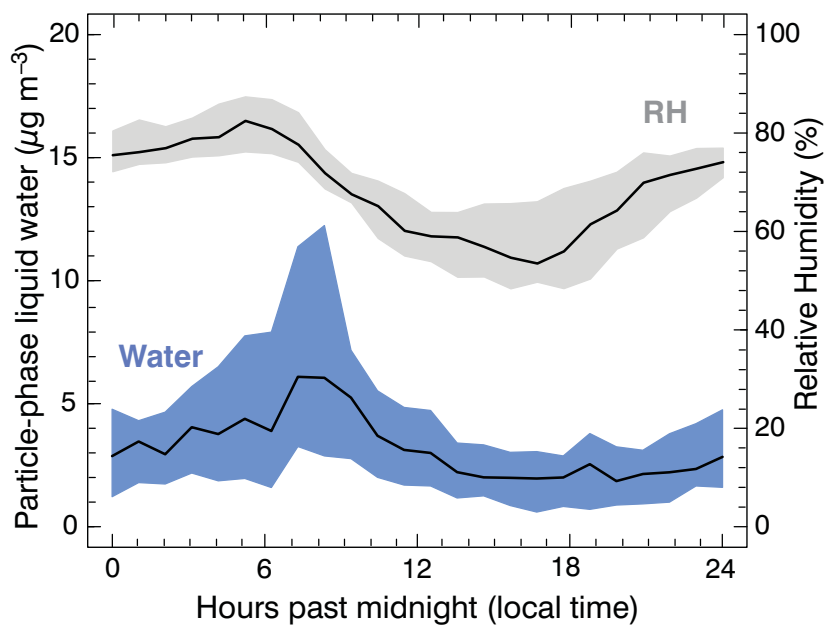

Figure 6. Campaign-averaged diel profiles of total particle-phase liquid water mass concentrations and RH binned into hourly intervals. The central lines indicate the median and the shaded regions indicate the interquartile range.

One would expect that the presence of sulfates would result in more hygroscopic aerosol in Alabama compared to the pristine Amazon rainforest.

Figure 4 summarizes trends of particle-phase liquid water $\left(V_{\mathrm{w}}\right)$ throughout the campaign at the $\mathrm{RH}$ encountered in the instrument. Measured water concentrations always exceeded $0 \mu \mathrm{g} \mathrm{m}^{-3}$, typically varied between 1 and $5 \mu \mathrm{g} \mathrm{m}^{-3}$, and peaked at $73 \mu \mathrm{g} \mathrm{m}^{-3}$ on 17 June. The campaign timeseries data indicate a strong diel cycle for $V_{\mathrm{w}}$. A campaignaverage representation of the diel cycle is presented in Fig. 6 . We note that this average diel cycle was suppressed during periods with heavy washout. An analysis contrasting selected time periods is provided in Appendix A. Figure 6 shows that water volume peaked during the early morning hours $\sim$ 07:00 to 09:00 LT. On average, the median value for water concentrations was $2.9 \mu \mathrm{g} \mathrm{m}^{-3}$, and the interquartile range was between 1.3 and $4.9 \mu \mathrm{g} \mathrm{m}^{-3}$ (Table 1). For 07:00 to 09:00 LT, however, the average median value for water mass concentrations was $5.8 \mu \mathrm{g} \mathrm{m}^{-3}$. The start of the decreasing transition for RH occurred in the morning at approximately 06:00 LT. The peak in water content occurred shortly after RH decreased and RH continued its decline until it increased again at 16:00 LT. Water mass concentrations leveled off after the morning peak, and despite the RH increase after 16:00 LT, water mass concentrations did not experience a noticeable increase in response during that time period. The partial decorrelation of RH and water volume suggests that either aerosol dry volume or aerosol hygroscopicity evolved during the day.

The evolution of composition is demonstrated further by the volumetric growth factor data. Figure 7 shows the diurnal profile of $\mathrm{gf}_{\mathrm{vol}}$ overlaid with expected $\mathrm{gf}_{\mathrm{vol}}$ assuming an invariant $\kappa$ throughout the day. In the Appendix, analysis is

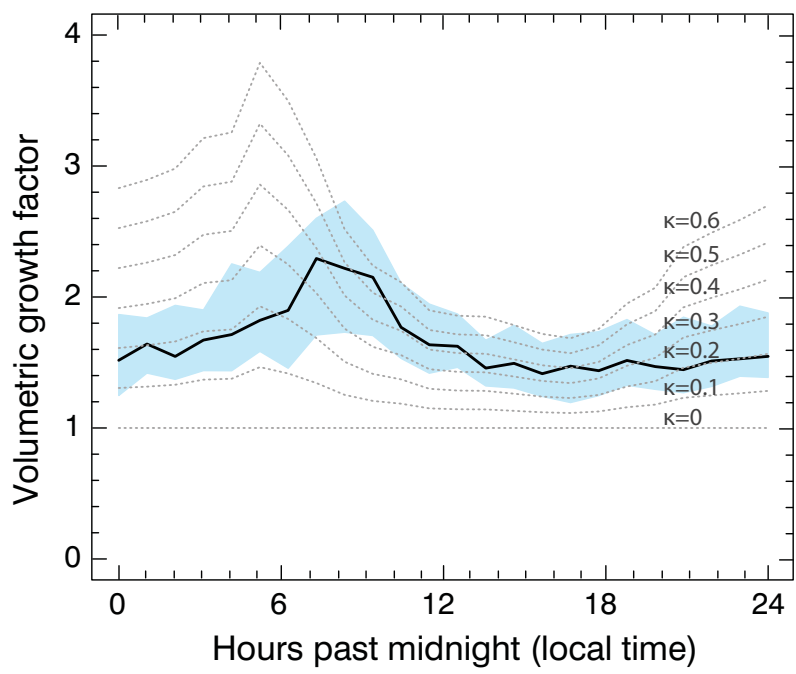

Figure 7. Diel profile of volumetric growth factor, $\mathrm{gf}_{\mathrm{vol}}$, binned into hourly intervals. The central lines indicate the median and the shaded area represents interquartile range. Grey dotted lines indicating median growth factors that were calculated using the same $\mathrm{RH}$ and dry volume, and assumed $\kappa$ values ranging from 0 to 0.6 .

performed for a volumetric growth factor profile for a single day as an illustrative example of a day with no rainfall. The data show that $\mathrm{gf}_{\mathrm{vol}}$ is always higher than 1 , and exceeds 2 between 07:00 and 09:00 LT. Overall, the $\mathrm{gf}_{\mathrm{vol}}$ median is 1.61 (Table 1). The data also show that the observed interquartile range for $\mathrm{gf}_{\mathrm{vol}}$ is between 1.37 and 2.01. These values are similar to those found during the Pittsburgh Air Quality Study (Khlystov et al., 2005). The overlaid expected growth factor for different values of $\kappa$ in the plot suggest that the aerosol hygroscopicity during the campaign changed systematically throughout the day, which is further explored in the diel cycle of $\kappa_{\mathrm{vol}}$ shown in Fig. 8. Overall, the median observed value for $\kappa_{\mathrm{vol}}$ is 0.27 and the interquartile range is from 0.14 to 0.46 . At night, $\kappa_{\mathrm{vol}}$ is steady at median values of $\sim 0.18$ and quartiles of $\sim 0.08$ to 0.3 . After 07:00 LT, $\kappa_{\mathrm{vol}}$ increases to about a median value of $\sim 0.48$ and quartiles of $\sim 0.2$ to 0.7 , followed by a gradual decrease throughout the rest of the day. The hygroscopicity statistics for the two size modes are summarized in Table 1. Medians of $\kappa$ for the smaller and larger diameter mode average to $\kappa_{\mathrm{D} 1}=0.13$ and $\kappa_{\mathrm{D} 2}=0.29$. In comparison, medians for $\kappa_{\mathrm{vol}}$ average to 0.27 , which more closely matches $\kappa_{\mathrm{D} 2}$ than $\kappa_{\mathrm{D} 1} . \kappa_{\mathrm{D} 1}$ also exhibits greater variability than either $\kappa_{\mathrm{vol}}$ or $\kappa_{\mathrm{D} 2}$, which is most likely attributable to noisiness in the fittings on a scan by scan basis that increases variability in the diameter growth factors for the mode.

The measured $\kappa_{\mathrm{vol}}$ are consistent with a mix of hygroscopic organic and inorganic compounds (Petters and Kreidenweis, 2007; Kreidenweis et al., 2008; Suda et al., 2012). The observed $\kappa_{\mathrm{vol}}$ values are significantly larger than those in organic-dominated environments encountered in remote 

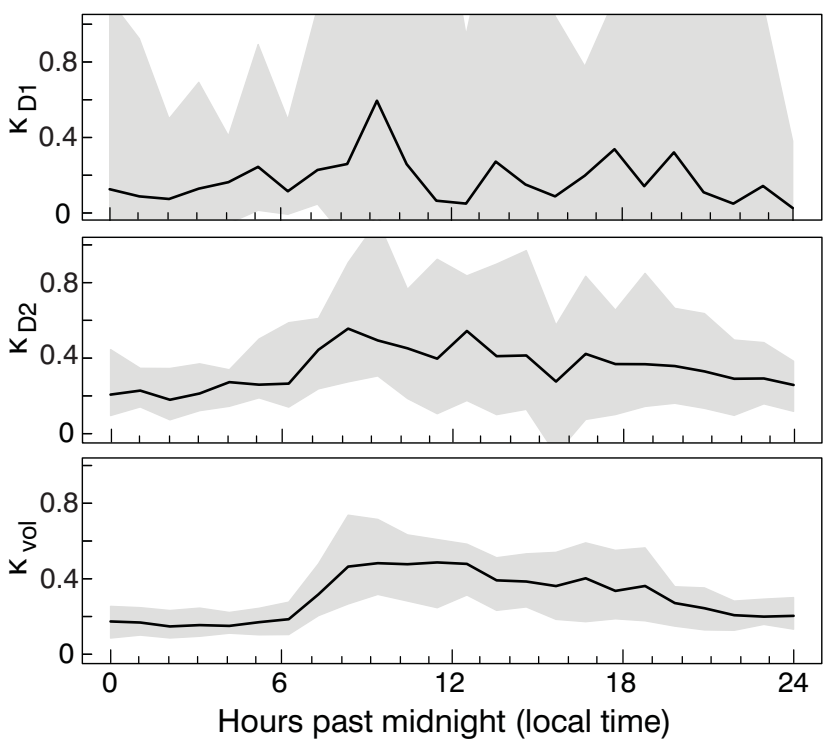

Figure 8. The top, middle, and bottom panels depict diurnal trends of smaller diameter mode, larger diameter mode, and volumetric $\kappa$, respectively. The trends are campaign-averaged and binned into hourly intervals. The central lines indicate the median values and the shaded area represents interquartile range.

continental forests (Gunthe et al., 2009; Sihto et al., 2011; Levin et al., 2012; Mikhailov et al., 2013), which vary between which vary between 0.1 and 0.2 . In these studies the aerosols were dried prior to measurement. We therefore also tested whether drying removed semi-volatile compounds and thus bias the observed $\kappa_{\mathrm{vol}}$

Results for the diel cycle of the semi-volatile fraction computed from Eqs. (7) and (11) are summarized Fig. 9. No clear diel trend is noticeable. At times the average semivolatile volume concentration is negative. However, the $95 \%$ confidence interval of the mean consistently envelops zero. This is consistent with the null hypothesis that no semivolatiles were removed in our preconditioning system and that the measurement has random error. We note that the confidence limits are $\sim \pm 0.5 \mu \mathrm{g} \mathrm{m}^{-3}$, which implies that pointto-point variability in the semi-volatile retrieval led to significant uncertainty. Losses of semi-volatile material less than $0.5 \mu \mathrm{g} \mathrm{m}^{-3}$ may have occurred but were undetectable with our method.

The diel evolution of the hygroscopic species sulfate, nitrate, ammonia, and WSOM is shown in Fig. 10. Ammonia and WSOM are approximately constant, while sulfate and nitrate show a diel cycle with a daytime maximum. We note that these speciated compounds only represent a subsection of the total aerosol since dust and elemental carbon are not included. Dust and elemental carbon are nonhygroscopic and therefore will not affect total water mass. Their presence will, however, lower the derived net $\kappa$ value of the aerosol. Overall, the sum of the median mass concentrations for sulfate

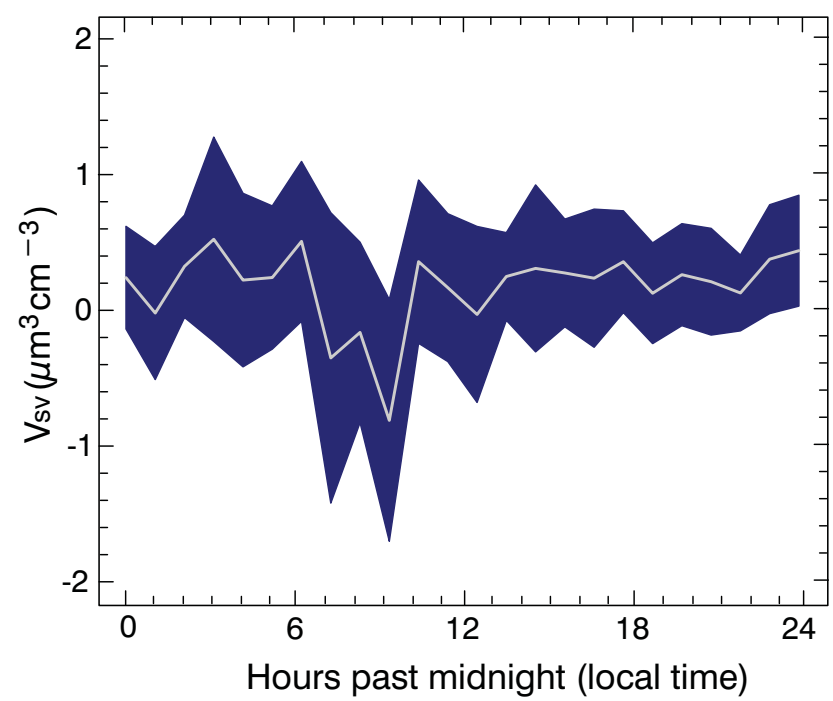

Figure 9. Diurnal trend of semi-volatile volumes lost during drying binned into hourly intervals. The central white line shows the mean of the measurements. The shaded blue area indicates a $95 \%$ confidence interval for the mean.

$\left(1.7 \mu \mathrm{g} \mathrm{m}^{-3}\right)$, nitrate $\left(0.07 \mu \mathrm{g} \mathrm{m}^{-3}\right)$, ammonia $\left(0.47 \mu \mathrm{g} \mathrm{m}^{-3}\right)$, and WSOM $\left(3.15 \mu \mathrm{g} \mathrm{m}^{-3}\right)$ is $5.39 \mu \mathrm{g} \mathrm{m}^{-3}$, and these species likely played an important role in governing aerosol water uptake during SOAS.

\section{Discussion}

The dynamics governing the total water volume that is available for water-mediated partitioning and condensed aqueousphase reactions are complex. First, our results show that a minimum of $7 \%$ of the aerosol volume is composed of water at the measured RH. Day-to-day variations in aerosol hygroscopicity are relatively minor, and total water volumes scale with dry aerosol volume and RH. The fractional water content is highest during the early morning hours when temperatures are lowest and RH is at a maximum. During those times, volume growth factors exceed 2 , implying that the aerosol composition is dominated by water. Second, on timescales longer than the diel cycle, dry aerosol volume is the dominant determinant of absolute water content. For example, between 3 and 9 June (Fig. 4), dry aerosol volume increased from 1 to $10 \mu \mathrm{m}^{3} \mathrm{~cm}^{-3}$, with concomitant increases in water volumes. Dry aerosol volume concentrations result from a balance in production (emissions and secondary production via chemical reactions) and removal (dry deposition, washout, and venting to the free troposphere) processes. The buildup of dry aerosol volume during stagnation events seems to be tied to the meteorological conditions. Warm temperatures, high actinic flux, and absence of deep convection and precipitation lead to accumulation of aerosol volume. The availability of a significant aqueous phase (by total volume) is thus correlated 
with, and contingent on, suitable weather conditions. Finally, the diel cycle of aerosol hygroscopicity suggests that significant changes in aerosol composition may occur on the timescale of a few hours. This is supported by changes in the inorganic aerosol fraction derived from the PILS measurements shown in Fig. 10e. Variation ranges from 20 to $80 \%$ for the inorganic fraction and the diel cycle in organic fraction mimics that of $\kappa$ (Fig. 10f). However, the actual relationship between chemical composition and $\kappa$ is complex since $\kappa$ may strongly vary with water content (or RH) for concentrated solutions (Kreidenweis et al., 2008). Assuming that the PILS-measured chemical composition captures most of the species responsible for water uptake, and assuming a representative composition for the WSOM fraction, we estimated the RH dependence using the E-AIM model (Clegg et al., 1998). These calculations show that the reduction of $\mathrm{RH}$ from 90 to $40 \%$ may cause a $60 \%$ increase in $\kappa$ (see Supplement). The diel fluctuation in $\kappa_{\mathrm{vol}}$ is from 0.14 to 0.46 . Notably, the aerosol is most hygroscopic when the fractional water content is larger, which is consistent with the modeled $\mathrm{RH}$ dependency of $\kappa$. The magnitude of the RH dependence, however, is insufficient to explain the full diel $\kappa$ cycle, which is driven by a combination of the two effects. We note that deconvolution of the two effects will require closure calculations between time-resolved chemical composition and $\kappa$ that are contingent upon complete speciation of the aerosol (including black carbon and dust), detailed information about the composition of WSOM, and estimation of aerosol solubility and density (see Supplement).

Figure 11 shows that there was no strong diel profile in dry aerosol volume. Thus diel changes in aerosol hygroscopicity are indicative of dynamic aerosol chemistry that does not involve major volume changes. Another possible explanation for the observed $\kappa_{\mathrm{vol}}$ changes are chemical transformations of the organic fraction itself that lead to corresponding changes in $\kappa_{\text {org }}$. Specifically, $\kappa_{\text {org }}$ has shown to increase with higher oxygen-to-carbon ratio (Jimenez et al., 2009), smaller molecular size (Petters et al., 2009b), and higher solubility in water (Petters and Kreidenweis, 2008). The presence of an aqueous phase combined with the morning actinic flux could drive aqueous-phase oxidation reactions or lead to hydrolysis reactions resulting in smaller, more oxidized, and watersoluble organic molecules or ions.

Perhaps consistent with aqueous-phase processes, the hygroscopicity parameter $\kappa$ increases with particle size, similar to trends of $\kappa$ with particle size were observed in previous field studies (Gunthe et al., 2009; Wiedensohler et al., 2009; Levin et al., 2012). The higher $\kappa$ values for the larger mode suggest the presence of more hygroscopic solutes such as more oxidized or hydrolyzed organic species, sulfates, or nitrates. A direct consequence of the size dependence is that the aqueous-phase volume is predominately located with the larger particle sizes both due to the larger dry aerosol volume and the larger hygroscopicity. This initiates the following question: of the three parameters influencing particle-phase
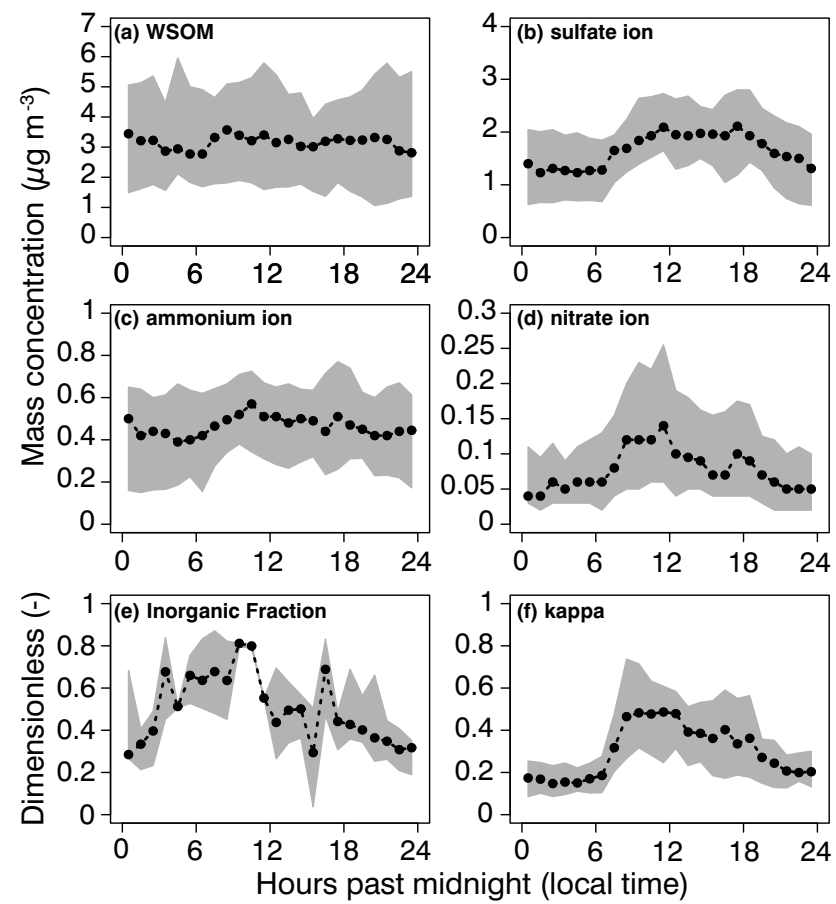

Figure 10. Diurnal trend of select aerosol chemical species measured by PILS-IC and WSOM calculated from PILS-WSOC. The central black line shows the median of the measurements. The shaded area indicates the interquartile range. Panel (e) shows the ratio of $\sum(b)+(c)+(d)$ over $\sum(a)+(b)+(c)+(d)$. Panel (f) is identical to Fig. 8.

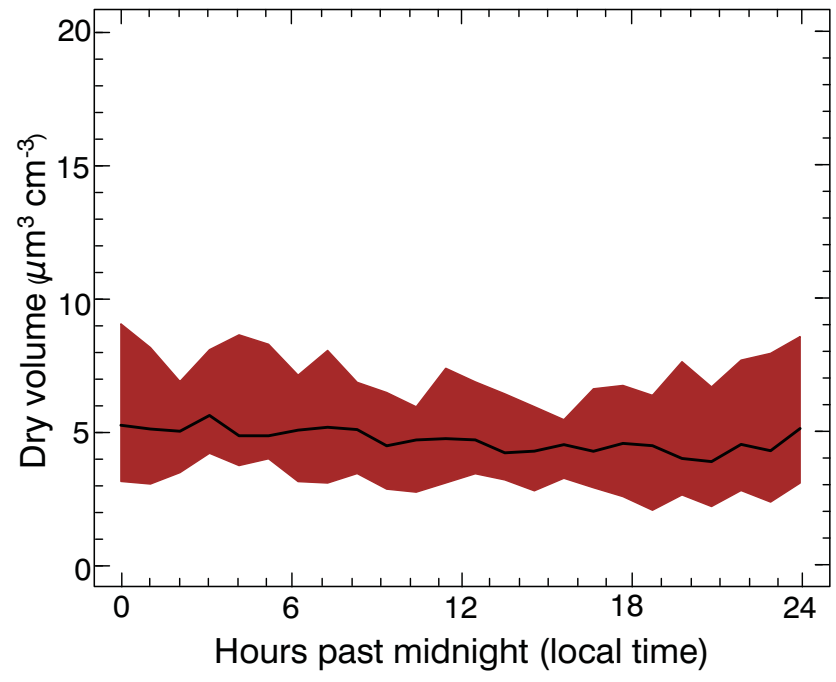

Figure 11. Diurnal trend of dry aerosol volumes binned into hourly intervals. The central black line shows the median of the measurements. The shaded red area indicates the interquartile range.

liquid water (dry aerosol volume, hygroscopicity, and RH), which are the most important under ambient conditions?

We address this question using sensitivity analysis following the approach of Feingold (2003) and McFiggans 
et al. (2006). The sensitivity is defined as $S\left(X_{i}\right)=$ $\partial \ln V_{\mathrm{w}} / \partial \ln X_{i}$, where $X_{i}$ is one of $V_{\mathrm{d}}, \mathrm{RH}$, or $\kappa_{\mathrm{vol}}$. Comparing values of $S\left(X_{i}\right)$ describes their relative importance given equal perturbations $\delta V_{\mathrm{d}}, \delta \mathrm{RH}$, or $\delta \kappa_{\mathrm{vol}}$. Based on Eq. (1), sensitivities $S\left(\kappa_{\mathrm{vol}}\right)$ and $S\left(V_{\mathrm{d}}\right)=1$, while $S(\mathrm{RH})=1 /(1-$ $\mathrm{RH})$. These sensitivities, combined with values for $\delta X_{i}$, are summarized in Table 3. The interpretation of $S\left(X_{i}\right)=1$ is that, for example, a $10 \%$ relative change in parameter $X_{i}$ will lead to a $10 \%$ relative change in $V_{\mathrm{w}}$. Changes in hygroscopicity, dry aerosol volume, and $\mathrm{RH}$ are potentially crosscorrelated. For example, the condensation of sulfuric acid onto organic aerosol will lead to both increases in $\kappa$ and $V_{\mathrm{d}}$, thereby influencing $V_{\mathrm{w}}$ via both pathways. In contrast, the condensation of nonhygroscopic organic material (i.e., $\kappa=0$ ) will lead to no increase in $V_{\mathrm{w}}$ as the effects of increased volume and decreased hygroscopicity cancel after application of the Zdanovskii-Stokes-Robinson (ZSR) mixing rule for $\kappa$ (Petters and Kreidenweis, 2007). From observations during SOAS, the perturbations $\delta \kappa$ and $\delta V_{\mathrm{d}}$ are comparable, resulting in 0-200\% variability of $V_{\mathrm{w}}$ depending on the hygroscopicity of the compound that controls the variability of the dry aerosol volume. Although the relative variability in RH is typically lower than $\kappa$ or $V_{\mathrm{d}}$, the relative sensitivity of water volume to changes in $\mathrm{RH}$ is much larger. At $\mathrm{RH}=40,70$, and $90 \%, S(\mathrm{RH})=1.66,3.33$, and 10 , respectively. Thus, at $\mathrm{RH}=90 \%$, a $1 \%$ relative fluctuation in RH will be equivalent to controls on water content by a $10 \%$ change in dry aerosol volume. As a result, the diel trends in water are primarily controlled by changes in relative humidity. The strong dependence of $V_{\mathrm{w}}$ on relative humidity is similar to that reported in previous studies (i.e., Khlystov et al., 2005). Since dew points are relatively constant during the day at the site location (see Fig. 4), we believe that the diel $V_{\mathrm{w}}$ cycle is indirectly controlled by temperature. Correlations between ambient temperature, relative humidity, and particle-phase liquid water can potentially obfuscate the attribution of semi-volatile partitioning into the condensed phase to either the presence of water due to increased RH or reduced vapor pressure due to reduced temperature. Although this conceptual distinction is important, it is irrelevant for this study because loss of semi-volatile volumes $V_{\mathrm{sv}}$ during our drying procedure was not statistically discernible (Fig. 9). The absence of this effect is likely due to the mismatch of residence time $(<10 \mathrm{~s})$ and slow equilibration time of the organic phase. This can occur after a perturbation in the gas-phase saturation ratio, which is systemdependent and may exceed $60 \mathrm{~min}$ (Riipinen et al., 2010; Cappa and Jimenez et al., 2010). For an improved methodology, one will need to reduce the uncertainty to resolve removal of less than $0.5 \mu \mathrm{g} \mathrm{m}^{-3}$ amounts, establish volatility limits that can be detected using a proxy system, lengthen residence time between the exit of the cold trap and SMPS to ensure full equilibration, and test whether the conclusion is valid when single particle sizes are considered.
Table 3. Table of sensitivity ratios $S\left(X_{i}\right)$ based on Eq. (1) for $X_{i}$ equal to $\kappa_{\mathrm{vol}}, V_{\mathrm{d}}$, and RH. The table also reports the typical range of these parameters during the SOAS campaign.

\begin{tabular}{llll}
\hline$X_{i}$ & $S\left(X_{i}\right)$ & Typical range during SOAS & Average of range \\
\hline$\kappa_{\mathrm{vol}}$ & 1 & $0.1<\kappa_{\mathrm{vol}}<0.6$ & 0.3 \\
$V_{\mathrm{d}}$ & 1 & $1<V_{\mathrm{d}}<10 \mu \mathrm{g} \mathrm{m}^{-3}$ & $5 \mu \mathrm{g} \mathrm{m}^{-3}$ \\
$\mathrm{RH}$ & $\frac{1}{1-\mathrm{RH}}$ & $0.4<\mathrm{RH}<1$ & 0.7 \\
\hline
\end{tabular}

\section{Conclusions}

We present measurements of dry aerosol volume, particlephase liquid water, and dry aerosol volume changes that may occur during particle drying. Six weeks of continuous in situ measurements of ambient aerosols were obtained during the SOAS campaign at Talladega National Forest in Brent, AL from 3 June to 15 July 2013. Aqueous-phase liquid water was always present, comprising a minimum of $7 \%$ of the aerosol volume at the measured RH. Water mass concentrations at the RH encountered in the instrument typically ranged from 1 to $5 \mu \mathrm{g} \mathrm{m}^{-3}$. Liquid water was the dominant aerosol constituent from $\sim$ 07:00 to 09:00 LT. The diel water-content cycle was dominated by changes in RH, which mostly fluctuated due to changes in temperature. A strong diel cycle in aerosol hygroscopicity is consistent with observed systematic changes in aerosol composition and a water-content dependency of $\kappa$. Aerosol hygroscopicity increased with particle size. The method of particle drying used in this study did not lead to removal of significant material that was associated with the aqueous phase. 


\section{Appendix A}

Conclusions based on campaign-based average diel cycles may be influenced by different regimes. To explore the possible influence of averaging, we repeat the analysis performed in Fig. 7 for a single day in Fig. A1. Comparison of Figs. 7 and A1 suggests that the reported diel trend accurately captures the behavior for a single day. An unusually cold and rainy period occurred between 4 and 8 July 2013 . During that time, aerosol volume was low and diel temperature and RH fluctuations were minimal. Figure A2 contrasts the diel cycle for particle-phase liquid water for a stagnation event with a pronounced diel cycle and the cold period. The data show that no diel cycle was observed during this atypical period, suggesting that conclusions reached about typical regional southeastern US aerosol must be interpreted in the context of the meteorological setting.

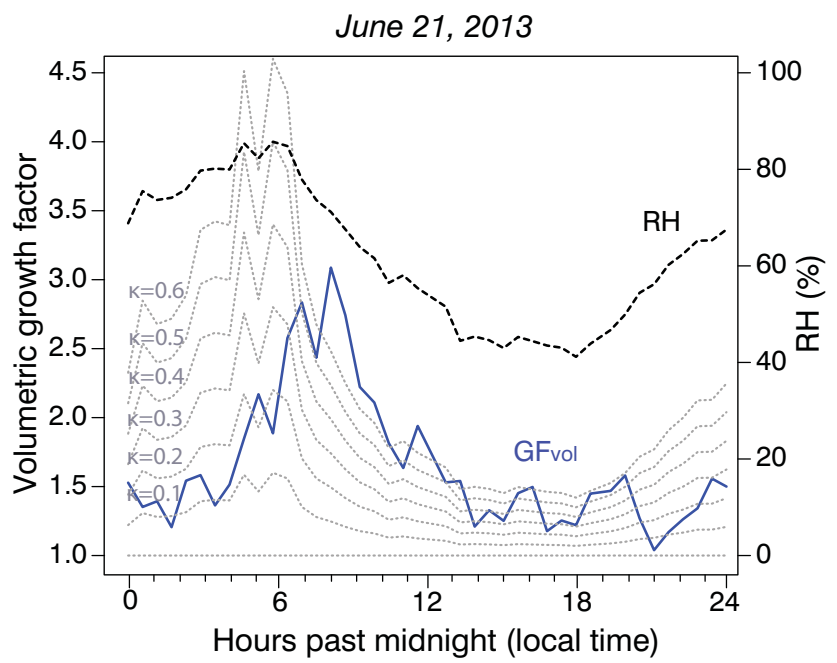

Figure A1. Same as Fig. 7 but for 21 June 2013, a day with no rainfall. Grey dotted lines indicating median growth factors that were calculated using the same RH and dry volume, and assumed $\kappa$ values ranging from 0 to 0.6 . The black dotted line indicates the RH.

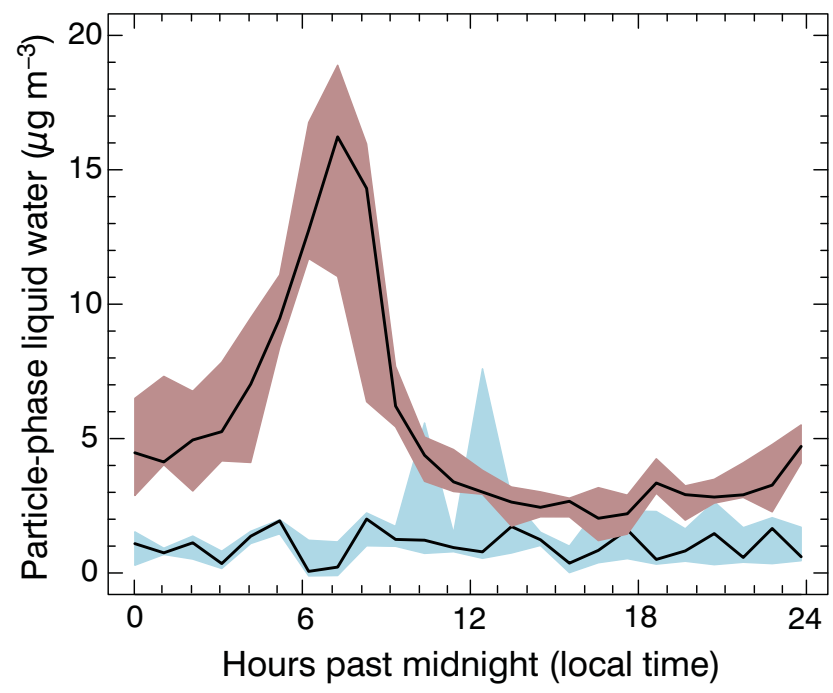

Figure A2. Comparison of particle-phase liquid water for a 5-day period with heavy rainfall (4-8 July, blue) vs. a 5-day period with no rainfall (18-22 June, brown). The central lines indicate the median, and the shaded regions indicate the interquartile range. 


\section{The Supplement related to this article is available online at doi:10.5194/acp-14-10911-2014-supplement.}

Acknowledgements. This material is based upon work funded by National Science Foundation grant AGS-1242155. S. R. Suda and M. D. Petters acknowledge support from the US Department of Energy grant DE-SC0006633. We thank the Atmospheric Administration, Atmospheric Research \& Analysis Inc., for providing meteorological and TEOM data for the SEARCH site, as well as Eric Edgerton, who has been running the SEARCH network since 1998. We also thank the Environmental Protection Agency, the National Oceanic and National Center for Atmospheric Research, the Electric Power Research Institute, and all of the SOAS participants for their help and support during the SOAS campaign. We thank the two anonymous referees for taking the time to provide in-depth constructive reviews, helping us to significantly improve the manuscript.

Edited by: N. Riemer

\section{References}

Asa-Awuku, A., Nenes, A., Gao, S., Flagan, R. C., and Seinfeld, J. H.: Water-soluble SOA from Alkene ozonolysis: composition and droplet activation kinetics inferences from analysis of CCN activity, Atmos. Chem. Phys., 10, 1585-1597, doi:10.5194/acp10-1585-2010, 2010.

Barley, M., Topping, D. O., Jenkin, M. E., and McFiggans, G.: Sensitivities of the absorptive partitioning model of secondary organic aerosol formation to the inclusion of water, Atmos. Chem. Phys., 9, 2919-2932, doi:10.5194/acp-9-2919-2009, 2009.

Berg, O. H., Swietlicki, E., and Krejci, R.: Hygroscopic growth of aerosol particles in the marine boundary layer over the $\mathrm{Pa}$ cific and Southern Oceans during the First Aerosol Characterization Experiment (ACE 1), J. Geophys. Res.-Atmos., 103, 1653516545, doi:10.1029/97jd02851, 1998.

Bertram, A. K., Martin, S. T., Hanna, S. J., Smith, M. L., Bodsworth, A., Chen, Q., Kuwata, M., Liu, A., You, Y., and Zorn, S. R.: Predicting the relative humidities of liquid-liquid phase separation, efflorescence, and deliquescence of mixed particles of ammonium sulfate, organic material, and water using the organic-to-sulfate mass ratio of the particle and the oxygen-tocarbon elemental ratio of the organic component, Atmos. Chem. Phys., 11, 10995-11006, doi:10.5194/acp-11-10995-2011, 2011.

Bilde, M., Svenningsson, B., Monster, J., and Rosenorn, T.: Evenodd alternation of evaporation rates and vapor pressures of C3C9 dicarboxylic acid aerosols, Environ. Sci. Technol., 37, 13711378, doi:10.1021/es0201810, 2003.

Booth, A. M., Barley, M. H., Topping, D. O., McFiggans, G., Garforth, A., and Percival, C. J.: Solid state and sub-cooled liquid vapour pressures of substituted dicarboxylic acids using Knudsen Effusion Mass Spectrometry (KEMS) and Differential Scanning Calorimetry, Atmos. Chem. Phys., 10, 4879-4892, doi:10.5194/acp-10-4879-2010, 2010.

Calvert, J. G., Lazrus, A., Kok, G. L., Heikes, B. G., Walega, J. G., Lind, J., and Cantrell, C. A.: Chemical Mechanisms of Acid Generation in the Troposphere, Nature, 317, 27-35, doi:10.1038/317027a0, 1985.

Cappa, C. D. and Jimenez, J. L.: Quantitative estimates of the volatility of ambient organic aerosol, Atmos. Chem. Phys., 10, 5409-5424, doi:10.5194/acp-10-5409-2010, 2010.

Carlton, A. G. and Turpin, B. J.: Particle partitioning potential of organic compounds is highest in the Eastern US and driven by anthropogenic water, Atmos. Chem. Phys., 13, 10203-10214, doi:10.5194/acp-13-10203-2013, 2013.

Carlton, A. G., Wiedinmyer, C., and Kroll, J. H.: A review of Secondary Organic Aerosol (SOA) formation from isoprene, Atmos. Chem. Phys., 9, 4987-5005, doi:10.5194/acp-9-4987-2009, 2009.

Carlton, A. G., Pinder, R. W., Bhave, P. V., and Pouliot, G. A.: To What Extent Can Biogenic SOA be Controlled?, Environ. Sci. Technol., 44, 3376-3380, doi:10.1021/es903506b, 2010.

Chan, M. N., Surratt, J. D., Claeys, M., Edgerton, E. S., Tanner, R. L., Shaw, S. L., Zheng, M., Knipping, E. M., Eddingsaas, N. C., Wennberg, P. O., and Seinfeld, J. H.: Characterization and Quantification of Isoprene-Derived Epoxydiols in Ambient Aerosol in the Southeastern United States, Environ. Sci. Technol., 44, 4590 4596, doi:10.1021/es100596b, 2010.

Clegg, S. L., Brimblecombe, P., and Wexler, A. S.: Thermodynamic Model of the System $\mathrm{H}^{+}-\mathrm{NH}_{4}^{+}-\mathrm{Na}^{+}-\mathrm{SO}_{4}^{2-}-\mathrm{NO}_{3}^{-}$$\mathrm{Cl}^{-}-\mathrm{H}_{2} \mathrm{O}$ at $298.15 \mathrm{~K}$, J. Phys. Chem. A, 102, 2155-2171, doi:10.1021/jp973043j, 1998.

Cruz, C. N. and Pandis, S. N.: A study of the ability of pure secondary organic aerosol to act as cloud condensation nuclei, Atmos. Environ., 31, 2205-2214, doi:10.1016/S13522310(97)00054-X, 1997.

Dick, W. D., Saxena, P., and McMurry, P. H.: Estimation of water uptake by organic compounds in submicron aerosols measured during the Southeastern Aerosol and Visibility Study, J. Geophys. Res.-Atmos., 105, 1471-1479, doi:10.1029/1999jd901001, 2000.

Ding, X., Zheng, M., Yu, L. P., Zhang, X. L., Weber, R. J., Yan, B., Russell, A. G., Edgerton, E. S., and Wang, X. M.: Spatial and seasonal trends in biogenic secondary organic aerosol tracers and water-soluble organic carbon in the southeastern United States, Environ. Sci. Technol., 42, 5171-5176, doi:10.1021/es7032636, 2008.

Duplissy, J., Gysel, M., Sjogren, S., Meyer, N., Good, N., Kammermann, L., Michaud, V., Weigel, R., Martins dos Santos, S., Gruening, C., Villani, P., Laj, P., Sellegri, K., Metzger, A., McFiggans, G. B., Wehrle, G., Richter, R., Dommen, J., Ristovski, Z., Baltensperger, U., and Weingartner, E.: Intercomparison study of six HTDMAs: results and recommendations, Atmos. Meas. Tech., 2, 363-378, doi:10.5194/amt-2-363-2009, 2009.

Engelhart, G. J., Hildebrandt, L., Kostenidou, E., Mihalopoulos, N., Donahue, N. M., and Pandis, S. N.: Water content of aged aerosol, Atmos. Chem. Phys., 11, 911-920, doi:10.5194/acp-11911-2011, 2011.

Ervens, B., Turpin, B. J., and Weber, R. J.: Secondary organic aerosol formation in cloud droplets and aqueous particles (aqSOA): a review of laboratory, field and model studies, Atmos. Chem. Phys., 11, 11069-11102, doi:10.5194/acp-1111069-2011, 2011. 
Feingold, G.: Modeling of the first indirect effect: Analysis of measurement requirements, Geophys. Res. Lett., 30, 1997, doi:10.1029/2003g1017967, 2003.

Gunthe, S. S., King, S. M., Rose, D., Chen, Q., Roldin, P., Farmer, D. K., Jimenez, J. L., Artaxo, P., Andreae, M. O., Martin, S. T., and Pöschl, U.: Cloud condensation nuclei in pristine tropical rainforest air of Amazonia: size-resolved measurements and modeling of atmospheric aerosol composition and CCN activity, Atmos. Chem. Phys., 9, 7551-7575, doi:10.5194/acp-9-75512009, 2009.

Gysel, M., Weingartner, E., and Baltensperger, U.: Hygroscopicity of aerosol particles at low temperatures. 2. Theoretical and experimental hygroscopic properties of laboratory generated aerosols, Environ. Sci. Technol., 36, 63-68, doi:10.1021/es010055g, 2002.

Gysel, M., McFiggans, G. B., and Coe, H.: Inversion of tandem differential mobility analyser (TDMA) measurements, J. Aerosol Sci., 40, 134-151, doi:10.1016/j.jaerosci.2008.07.013, 2009.

Hallquist, M., Wenger, J. C., Baltensperger, U., Rudich, Y., Simpson, D., Claeys, M., Dommen, J., Donahue, N. M., George, C., Goldstein, A. H., Hamilton, J. F., Herrmann, H., Hoffmann, T., Iinuma, Y., Jang, M., Jenkin, M. E., Jimenez, J. L., Kiendler-Scharr, A., Maenhaut, W., McFiggans, G., Mentel, Th. F., Monod, A., Prévôt, A. S. H., Seinfeld, J. H., Surratt, J. D., Szmigielski, R., and Wildt, J.: The formation, properties and impact of secondary organic aerosol: current and emerging issues, Atmos. Chem. Phys., 9, 5155-5236, doi:10.5194/acp-9-51552009, 2009.

Hatch, T. and Choate, S. P.: Statistical description of the size properties of non uniform particulate substances, J. Frankl. Inst., 207, 369-387, doi:10.1016/S0016-0032(29)91451-4, 1929.

Hatch, L. E., Creamean, J. M., Ault, A. P., Surratt, J. D., Chan, M. N., Seinfeld, J. H., Edgerton, E. S., Su, Y., and Prather, K. A.: Measurements of Isoprene-Derived Organosulfates in Ambient Aerosols by Aerosol Time-of-Flight Mass Spectrometry - Part 1: Single Particle Atmospheric Observations in Atlanta, Environ. Sci. Technol., 45, 5105-5111, doi:10.1021/es103944a, 2011.

Hecobian, A., Zhang, X., Zheng, M., Frank, N., Edgerton, E. S., and Weber, R. J.: Water-Soluble Organic Aerosol material and the light-absorption characteristics of aqueous extracts measured over the Southeastern United States, Atmos. Chem. Phys., 10, 5965-5977, doi:10.5194/acp-10-5965-2010, 2010.

Hegg, D. A., Covert, D. S., and Jonsson, H. H.: Measurements of size-resolved hygroscopicity in the California coastal zone, Atmos. Chem. Phys., 8, 7193-7203, doi:10.5194/acp-8-7193-2008, 2008.

Hoyle, C. R., Boy, M., Donahue, N. M., Fry, J. L., Glasius, M., Guenther, A., Hallar, A. G., Huff Hartz, K., Petters, M. D., Petäjä, T., Rosenoern, T., and Sullivan, A. P.: A review of the anthropogenic influence on biogenic secondary organic aerosol, Atmos. Chem. Phys., 11, 321-343, doi:10.5194/acp-11-321-2011, 2011.

Jaenicke, R.: Tropospheric aerosols, in: Aerosol-Cloud-Climate Interactions, edited by: Hobbs, P. V., Academic Press, San Diego, CA, 1-31, 1993.

Jimenez, J. L., Canagaratna, M. R., Donahue, N. M., Prevot, A. S. H., Zhang, Q., Kroll, J. H., DeCarlo, P. F., Allan, J. D., Coe, H., Ng, N. L., Aiken, A. C., Docherty, K. S., Ulbrich, I. M., Grieshop, A. P., Robinson, A. L., Duplissy, J., Smith, J. D., Wilson, K. R., Lanz, V. A., Hueglin, C., Sun, Y. L., Tian, J., Laaksonen, A., Raatikainen, T., Rautiainen, J., Vaattovaara, P., Ehn,
M., Kulmala, M., Tomlinson, J. M., Collins, D. R., Cubison, M. J., Dunlea, E. J., Huffman, J. A., Onasch, T. B., Alfarra, M. R., Williams, P. I., Bower, K., Kondo, Y., Schneider, J., Drewnick, F., Borrmann, S., Weimer, S., Demerjian, K., Salcedo, D., Cottrell, L., Griffin, R., Takami, A., Miyoshi, T., Hatakeyama, S., Shimono, A., Sun, J. Y., Zhang, Y. M., Dzepina, K., Kimmel, J. R., Sueper, D., Jayne, J. T., Herndon, S. C., Trimborn, A. M., Williams, L. R., Wood, E. C., Middlebrook, A. M., Kolb, C. E., Baltensperger, U., and Worsnop, D. R.: Evolution of Organic Aerosols in the Atmosphere, Science, 326, 1525-1529, doi:10.1126/science.1180353, 2009.

Kanakidou, M., Seinfeld, J. H., Pandis, S. N., Barnes, I., Dentener, F. J., Facchini, M. C., Van Dingenen, R., Ervens, B., Nenes, A., Nielsen, C. J., Swietlicki, E., Putaud, J. P., Balkanski, Y., Fuzzi, S., Horth, J., Moortgat, G. K., Winterhalter, R., Myhre, C. E. L., Tsigaridis, K., Vignati, E., Stephanou, E. G., and Wilson, J.: Organic aerosol and global climate modelling: a review, Atmos. Chem. Phys., 5, 1053-1123, doi:10.5194/acp-5-1053-2005, 2005.

Kelly, W. P. and McMurry, P. H.: Measurement of Particle Density by Inertial Classification of Differential Mobility AnalyzerGenerated Monodisperse Aerosols, Aerosol. Sci. Tech., 17, 199212, doi:10.1080/02786829208959571, 1992.

Khlystov, A., Stanier, C. O., Takahama, S., and Pandis, S. N.: Water content of ambient aerosol during the Pittsburgh air quality study, J. Geophys. Res.-Atmos., 110, D07S10, doi:10.1029/2004jd004651, 2005.

Kleindienst, T. E., Jaoui, M., Lewandowski, M., Offenberg, J. H., Lewis, C. W., Bhave, P. V., and Edney, E. O.: Estimates of the contributions of biogenic and anthropogenic hydrocarbons to secondary organic aerosol at a southeastern US location, Atmos. Environ., 41, 8288-8300, doi:10.1016/j.atmosenv.2007.06.045, 2007.

Knote, C., Hodzic, A., Jimenez, J. L., Volkamer, R., Orlando, J. J., Baidar, S., Brioude, J., Fast, J., Gentner, D. R., Goldstein, A. H., Hayes, P. L., Knighton, W. B., Oetjen, H., Setyan, A., Stark, H., Thalman, R., Tyndall, G., Washenfelder, R., Waxman, E., and Zhang, Q.: Simulation of semi-explicit mechanisms of SOA formation from glyoxal in aerosol in a 3-D model, Atmos. Chem. Phys., 14, 6213-6239, doi:10.5194/acp-14-6213-2014, 2014.

Knutson, E. O. and Whitby, K. T.: Aerosol classification by electric mobility: apparatus, theory, and applications, J. Aerosol Sci., 6, 443-451, doi:10.1016/0021-8502(75)90060-9, 1975.

Koponen, I. K., Riipinen, I., Hienola, A., Kulmala, M., and Bilde, M.: Thermodynamic properties of malonic, succinic, and glutaric acids: Evaporation rates and saturation vapor pressures, Environ. Sci. Technol., 41, 3926-3933, doi:10.1021/es0611240, 2007.

Kreidenweis, S. M., Petters, M. D., and DeMott, P. J.: Singleparameter estimates of aerosol water content, Environ. Res. Lett., 3, 035002, doi:10.1088/1748-9326/3/3/035002, 2008.

Levin, E. J. T., Prenni, A. J., Petters, M. D., Kreidenweis, S. M., Sullivan, R. C., Atwood, S. A., Ortega, J., DeMott, P. J., and Smith, J. N.: An annual cycle of size-resolved aerosol hygroscopicity at a forested site in Colorado, J. Geophys. Res.-Atmos., 117, 06201, doi:10.1029/2011jd016854, 2012.

Lewis, C. W., Klouda, G. A., and Ellenson, W. D.: Radiocarbon measurement of the biogenic contribution to summertime PM-2.5 ambient aerosol in Nashville, TN, Atmos. Environ., 38, 6053-6061, doi:10.1016/j.atmosenv.2004.06.011, 2004. 
Leibensperger, E. M., Mickley, L. J., Jacob, D. J., Chen, W.-T., Seinfeld, J. H., Nenes, A., Adams, P. J., Streets, D. G., Kumar, N., and Rind, D.: Climatic effects of 1950-2050 changes in US anthropogenic aerosols - Part 1: Aerosol trends and radiative forcing, Atmos. Chem. Phys., 12, 3333-3348, doi:10.5194/acp-12-33332012, 2012.

Liao, H. and Seinfeld, J. H.: Global impacts of gas-phase chemistryaerosol interactions on direct radiative forcing by anthropogenic aerosols and ozone, J. Geophys. Res.-Atmos., 110, D18208, doi:10.1029/2005jd005907, 2005.

Lim, Y. B., Tan, Y., Perri, M. J., Seitzinger, S. P., and Turpin, B. J.: Aqueous chemistry and its role in secondary organic aerosol (SOA) formation, Atmos. Chem. Phys., 10, 1052110539, doi:10.5194/acp-10-10521-2010, 2010.

Liu, J., Zhang, X., Parker, E., Veres, P. R., Roberts, J. M., Gouw, J. D., Hayes, P. L., Jimenez, J. L., Ellis, R., and Weber, R. J.: On the Partitioning of Soluble Organic Aerosol in Two Urban Atmospheres with Contrasting Emissions: Part 2 Gas and Particle Phase Formic Acid, J. Geophys. Res., 117, D00V21, doi:10.1029/2012JD017912, 2012.

Liu, B. Y. H., Pui, D. Y. H., Whitby, K. T., Kittelson, D. B., Kousaka, Y., and McKenzie, R. L.: The aerosol mobility chromatograph: A new detector for sulfuric acid aerosols, Atmos. Environ., 12, 99104, doi:10.1016/0004-6981(78)90192-0, 1978.

Malm, W. C., Sisler, J. F., Huffman, D., Eldred, R. A., and Cahill, T. A.: Spatial and Seasonal Trends in Particle Concentration and Optical Extinction in the United-States, J. Geophys. Res.Atmos., 99, 1347-1370, doi:10.1029/93jd02916, 1994.

Martin, S. T., Andreae, M. O., Althausen, D., Artaxo, P., Baars, H., Borrmann, S., Chen, Q., Farmer, D. K., Guenther, A., Gunthe, S. S., Jimenez, J. L., Karl, T., Longo, K., Manzi, A., Müller, T., Pauliquevis, T., Petters, M. D., Prenni, A. J., Pöschl, U., Rizzo, L. V., Schneider, J., Smith, J. N., Swietlicki, E., Tota, J., Wang, J., Wiedensohler, A., and Zorn, S. R.: An overview of the Amazonian Aerosol Characterization Experiment 2008 (AMAZE08), Atmos. Chem. Phys., 10, 11415-11438, doi:10.5194/acp10-11415-2010, 2010.

McFiggans, G., Artaxo, P., Baltensperger, U., Coe, H., Facchini, M. C., Feingold, G., Fuzzi, S., Gysel, M., Laaksonen, A., Lohmann, U., Mentel, T. F., Murphy, D. M., O’Dowd, C. D., Snider, J. R., and Weingartner, E.: The effect of physical and chemical aerosol properties on warm cloud droplet activation, Atmos. Chem. Phys., 6, 2593-2649, doi:10.5194/acp-6-2593-2006, 2006.

McMurry, P. H. and Stolzenburg, M. R.: On the Sensitivity of Particle-Size to Relative-Humidity for Los-Angeles Aerosols, Atmos. Environ., 23, 497-507, doi:10.1016/00046981(89)90593-3, 1989.

Mikhailov, E., Vlasenko, S., Niessner, R., and Pöschl, U.: Interaction of aerosol particles composed of protein and saltswith water vapor: hygroscopic growth and microstructural rearrangement, Atmos. Chem. Phys., 4, 323-350, doi:10.5194/acp-4-323-2004, 2004.

Mikhailov, E., Vlasenko, S., Rose, D., and Pöschl, U.: Mass-based hygroscopicity parameter interaction model and measurement of atmospheric aerosol water uptake, Atmos. Chem. Phys., 13, 717740, doi:10.5194/acp-13-717-2013, 2013.

Mitchem, L. and Reid, J. P.: Optical manipulation and characterisation of aerosol particles using a single-beam gradient force opti- cal trap, Chem. Soc. Rev., 37, 756-769, doi:10.1039/b609713h, 2008.

Murphy, D. M., Thomson, D. S., and Mahoney, T. M. J.: In situ measurements of organics, meteoritic material, mercury, and other elements in aerosols at 5 to 19 kilometers, Science, 282, 16641669, doi:10.1126/science.282.5394.1664, 1998.

Orsini, D., Ma, Y., Sullivan, A., Sierau, B. , Baumann, K., and Weber, R.: Refinements to the Particle-Into-Liquid Sampler (Pils) For Ground and Airborne Measurements Of Water Soluble Aerosol Composition, Atmos. Environ., 37, 1243-1259, doi:10.1016/S1352-2310(02)01015-4, 2003.

Patashnick, H., and Rupprecht, E. G.: Continuous Pm-10 Measurements Using the Tapered Element Oscillating Microbalance, J. Air Waste Manage., 41, 1079-1083, doi:10.1080/10473289.1991.10466903, 1991.

Pankow, J. F.: An Absorption-Model of the Gas Aerosol Partitioning Involved in the Formation of Secondary Organic Aerosol, Atmos. Environ., 28, 189-193, doi:10.1016/1352-2310(94)900949, 1994.

Pankow, J. F. and Chang, E. I.: Variation in the sensitivity of predicted levels of atmospheric organic particulate matter (OPM), Environ. Sci. Technol., 42, 7321-7329, doi:10.1021/es8003377, 2008.

Pankow, J. E., Seinfeld, J. H., Asher, W. E., and Erdakos, G. B.: Modeling the formation of secondary organic aerosol (SOA). 2. The predicted effects of relative humidity on aerosol formation in the alpha-pinene-, beta-pinene-, sabinene-, Delta(3)-Carene, and cyclohexene-ozone systems, Environ. Sci. Technol., 35, 1806-1817, doi:10.1021/es001321d, 2001.

Park, R. J., Jacob, D. J., Field, B. D., Yantosca, R. M., and Chin, M.: Natural and transboundary pollution influences on sulfate-nitrate-ammonium aerosols in the United States: Implications for policy, J. Geophys. Res.-Atmos., 109, D15204, doi:10.1029/2003jd004473, 2004.

Petters, M. D. and Kreidenweis, S. M.: A single parameter representation of hygroscopic growth and cloud condensation nucleus activity, Atmos. Chem. Phys., 7, 1961-1971, doi:10.5194/acp-71961-2007, 2007.

Petters, M. D. and Kreidenweis, S. M.: A single parameter representation of hygroscopic growth and cloud condensation nucleus activity - Part 2: Including solubility, Atmos. Chem. Phys., 8, 6273-6279, doi:10.5194/acp-8-6273-2008, 2008.

Petters, M. D., Carrico, C. M. Kreidenweis, S. M., Prenni, A. J., DeMott, P. J., Collett Jr., J. R., and H. Moosmüller, H.:, Cloud condensation nucleation ability of biomass burning aerosol, J. Geophys. Res., 114, D22205, doi:10.1029/2009JD012353, 2009a.

Petters, M. D., Kreidenweis, S. M., Prenni, A. J., Sullivan, R. C., Carrico, C. M., Koehler, K. A., and Ziemann, P. J.: Role of molecular size in cloud droplet activation, Geophys. Res. Lett., 36, L22801, doi:10.1029/2009g1040131, 2009b.

Pitchford, M., Malm, W., Schichtel, B., Kumar, N., Lowenthal, D., and Hand, J.: Revised algorithm for estimating light extinction from IMPROVE particle speciation data, J. Air Waste Manage., 57, 1326-1336, doi:10.3155/1047-3289.57.11.1326, 2007.

Pilinis, C., Pandis, S. N., and Seinfeld, J. H.: Sensitivity of direct climate forcing by atmospheric aerosols to aerosol size and composition, J. Geophys. Res., 100, 18739, doi:10.1029/95JD02119, 1995. 
Pöschl, U.: Atmospheric aerosols: Composition, transformation, climate and health effects, Angew. Chem. Int. Edit., 44, 75207540, doi:10.1002/anie.200501122, 2005.

Prisle, N. L., Engelhart, G. J., Bilde, M., and Donahue, N. M.: Humidity influence on gas-particle phase partitioning of $\alpha$-pinene + $\mathrm{O}_{3}$ secondary organic aerosol, Geophys. Res. Lett., 37, L01802, doi:10.1029/2009g1041402, 2010.

Rader, D. J. and McMurry, P. H.: Application of the tandem differential mobility analyzer to studies of droplet growth or evaporation, J. Aerosol Sci., 17, 771-787, doi:10.1016/00218502(86)90031-5, 1986.

Renbaum-Wolff, L., Grayson, J. W., Bateman, A. P., Kuwata, M., Sellier, M., Murray, B. J., Shilling, J. E., Martin, S. T., and Bertram, A. K.: Viscosity of $\alpha$-pinene secondary organic material and implications for particle growth and reactivity, P. Natl. Acad. Sci. USA, 110, 8014-8019, doi:10.1073/pnas.1219548110, 2013.

Riipinen, I., Pierce, J. R., Donahue, N. M., and Pandis, S. N.: Equilibration time scales of organic aerosol inside thermodenuders: Evaporation kinetics versus thermodynamics, Atmos. Environ., 44, 597-607, doi:10.1016/J.Atmosenv.2009.11.022, 2010.

Robinson, A. L., Donahue, N. M., Shrivastava, M. K., Weitkamp, E. A., Sage, A. M., Grieshop, A. P., Lane, T. E., Pierce, J. R., and Pandis, S. N.: Rethinking organic aerosols: Semivolatile emissions and photochemical aging, Science, 315, 1259-1262, doi:10.1126/science.1133061, 2007.

Rood, M. J., Larson, T. V., Covert, D. S., and Ahlquist, N. C.: Measurement of Laboratory and Ambient Aerosols with Temperature and Humidity Controlled Nephelometry, Atmos. Environ., 19, 1181-1190, doi:10.1016/0004-6981(85)90202-1, 1985.

Russell, L. M., Zhang, S. H., Flagan, R. C., Seinfeld, J. H., Stolzenburg, M. R., and Caldow, R.: Radially classified aerosol detector for aircraft-based submicron aerosol measurements, J. Atmos. Ocean Tech., 13, 598-609, doi:10.1175/15200426(1996)013<0598:RCADFA>2.0.CO;2, 1996.

Seinfeld, J. H. and Pandis, S. N.: Atmospheric Chemistry and Physics: From Air Pollution to Climate Change, 2nd Edn., J. Wiley, New York, 350-395, 2006.

Sihto, S.-L., Mikkilä, J., Vanhanen, J., Ehn, M., Liao, L., Lehtipalo, K., Aalto, P. P., Duplissy, J., Petäjä, T., Kerminen, V.-M., Boy, M., and Kulmala, M.: Seasonal variation of $\mathrm{CCN}$ concentrations and aerosol activation properties in boreal forest, Atmos. Chem. Phys., 11, 13269-13285, doi:10.5194/acp-11-13269-2011, 2011.

Snider, J. R. and Petters, M. D.: Optical particle counter measurement of marine aerosol hygroscopic growth, Atmos. Chem. Phys., 8, 1949-1962, doi:10.5194/acp-8-1949-2008, 2008.

Sorooshian, A., Hersey, S., Brechtel, F. J., Corless, A., Flagan, R. C., and Seinfeld, J. H.: Rapid, size-resolved aerosol hygroscopic growth measurements: Differential aerosol sizing and hygroscopicity spectrometer probe (DASH-SP), Aerosol Sci. Tech., 42, 445-464, doi:10.1080/02786820802178506, 2008.

Speer, R. E., Edney, E. O., and Kleindienst, T. E.: Impact of organic compounds on the concentrations of liquid water in ambient $\mathrm{PM}_{2.5}$, J. Aerosol Sci., 34, 63-77, doi:10.1016/S00218502(02)00152-0, 2003

Stanier, C. O., Khlystov, A. Y., Chan, W. R., Mandiro, M., and Pandis, S. N.: A method for the in situ measurement of fine aerosol water content of ambient aerosols: The dry-ambient aerosol size spectrometer (DAASS), Aerosol Sci. Tech., 38, 215-228, doi:10.1080/02786820390229525, 2004.

Stokes, R. H. and Robinson, R. A.: Interactions in Aqueous Nonelectrolyte Solutions. I. Solute-Solvent Equilibria, J. Phys. Chem., 70, 2126-2131, doi:10.1021/j100879a010, 1966.

Stolzenburg, M., Kreisberg, N., and Hering, S.: Atmospheric size distributions measured by differential mobility optical particle size spectrometry, Aerosol Sci. Tech., 29, 402-418, doi:10.1080/02786829808965579, 1998.

Stratmann, F., Kiselev, A., Wurzler, S., Wendisch, M., Heintzenberg, J., Charlson, R. J., Diehl, K., Wex, H., and Schmidt, S.: Laboratory studies and numerical simulations of cloud droplet formation under realistic supersaturation conditions, J. Atmos. Ocean Tech., 21, 876-887, doi:10.1175/15200426(2004)021<0876:LSANSO>2.0.CO;2, 2004.

Suda, S. R. and Petters, M. D.: Accurate Determination of Aerosol Activity Coefficients at Relative Humidities up to 99\% Using the Hygroscopicity Tandem Differential Mobility Analyzer Technique, Aerosol Sci. Tech., 47, 991-1000, doi:10.1080/02786826.2013.807906, 2013.

Suda, S. R., Petters, M. D., Matsunaga, A., Sullivan, R. C., Ziemann, P. J., and Kreidenweis, S. M.: Hygroscopicity frequency distributions of secondary organic aerosols, J. Geophys. Res.Atmos., 117, D04207, doi:10.1029/2011jd016823, 2012.

Swietlicki, E., Hansson, H. C., Hameri, K., Svenningsson, B., Massling, A., McFiggans, G., McMurry, P. H., Petaja, T., Tunved, P., Gysel, M., Topping, D., Weingartner, E., Baltensperger, U., Rissler, J., Wiedensohler, A., and Kulmala, M.: Hygroscopic properties of submicrometer atmospheric aerosol particles measured with H-TDMA instruments in various environments - a review, Tellus B, 60, 432-469, doi:10.1111/j.16000889.2008.00350.x, 2008.

Tang, I. N.: Chemical and size effects of hygroscopic aerosols on light scattering coefficients, J. Geophys. Res.-Atmos., 101, 19245-19250, doi:10.1029/96jd03003, 1996.

Topping, D. O. and McFiggans, G.: Tight coupling of particle size, number and composition in atmospheric cloud droplet activation, Atmos. Chem. Phys., 12, 3253-3260, doi:10.5194/acp-12-32532012, 2012.

Turpin, B. J. and Lim, H. J.: Species contributing to PM2.5 mass concentrations: revisiting common assumptions for estimating organic mass, Aerosol Sci. Tech., 35, 602-610, doi:10.1080/02786820119445, 2001.

Vaden, T. D., Imre, D., Beranek, J., Shrivastava, M., and Zelenyuk, A.: Evaporation kinetics and phase of laboratory and ambient secondary organic aerosol, P. Natl. Acad. Sci. USA, 108, 2190 2195, doi:10.1073/pnas.1013391108, 2011.

Wang, S. C. and Flagan, R. C.: Scanning Electrical Mobility Spectrometer, Aerosol Sci. Tech., 13, 230-240, doi:10.1080/02786829008959441, 1990.

Wex, H., Kiselev, A., Stratmann, F., Zoboki, J., and Brechtel, F.: Measured and modeled equilibrium sizes of $\mathrm{NaCl}$ and $\left(\mathrm{NH}_{4}\right)_{2} \mathrm{SO}_{4}$ particles at relative humidities up to $99.1 \%$, J. Geophys. Res.-Atmos., 110, D21212, doi:10.1029/2004jd005507, 2005.

Wexler, A. S. and Clegg, S. L.: Atmospheric aerosol models for systems including the ions $\mathrm{H}^{+}, \mathrm{NH}_{4}^{+}, \mathrm{Na}^{+}, \mathrm{SO}_{4}^{2-}, \mathrm{NO}_{3}^{-}, \mathrm{Cl}^{-}$, $\mathrm{Br}^{-}$, and $\mathrm{H}_{2} \mathrm{O}$, J. Geophys. Res.-Atmos., 107, ACH 14-11-ACH 14-14, doi:10.1029/2001jd000451, 2002. 
Wiedensohler, A., Cheng, Y. F., Nowak, A., Wehner, B., Achtert, P., Berghof, M., Birmili, W., Wu, Z. J., Hu, M., Zhu, T., Takegawa, N., Kita, K., Kondo, Y., Lou, S. R., Hofzumahaus, A., Holland, F., Wahner, A., Gunthe, S. S., Rose, D., Su, H., and Pöschl, U.: Rapid aerosol particle growth and increase of cloud condensation nucleus activity by secondary aerosol formation and condensation: A case study for regional air pollution in northeastern China, J. Geophys. Res.-Atmos., 114, D00G08, doi:10.1029/2008JD010884, 2009.
Zhou, Y., Zhang, H. F., Parikh, H. M., Chen, E. H., Rattanavaraha, W., Rosen, E. P., Wang, W. X., and Kamens, R. M.: Secondary organic aerosol formation from xylenes and mixtures of toluene and xylenes in an atmospheric urban hydrocarbon mixture: Water and particle seed effects (II), Atmos. Environ., 45, 3882-3890, doi:10.1016/j.atmosenv.2010.12.048, 2011. 